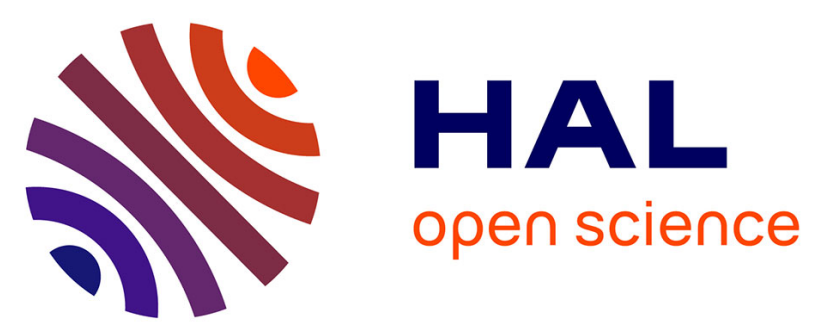

\title{
Comparative structural and vibrational investigations between cocoa butter (CB) and cocoa butter equivalent (CBE) by ESI/MALDI-HRMS, XRD, DSC, MIR and Raman spectroscopy
}

Serge Bresson, A. Lecuelle, F. Bougrioua, M. El Hadri, V. Baeten, M. Courty, S. Pilard, Sébastien Rigaud, V. Faivre

\section{To cite this version:}

Serge Bresson, A. Lecuelle, F. Bougrioua, M. El Hadri, V. Baeten, et al.. Comparative structural and vibrational investigations between cocoa butter $(\mathrm{CB})$ and cocoa butter equivalent $(\mathrm{CBE})$ by ESI/MALDI-HRMS, XRD, DSC, MIR and Raman spectroscopy. Food Chemistry, 2021, 363, pp.130319. 10.1016/j.foodchem.2021.130319 . hal-03270225

\section{HAL Id: hal-03270225 \\ https://hal.science/hal-03270225}

Submitted on 24 Jun 2021

HAL is a multi-disciplinary open access archive for the deposit and dissemination of scientific research documents, whether they are published or not. The documents may come from teaching and research institutions in France or abroad, or from public or private research centers.
L'archive ouverte pluridisciplinaire HAL, est destinée au dépôt et à la diffusion de documents scientifiques de niveau recherche, publiés ou non, émanant des établissements d'enseignement et de recherche français ou étrangers, des laboratoires publics ou privés. 


\title{
Comparative structural and vibrational investigations between cocoa butter (CB) and cocoa butter equivalent (CBE) by ESI/MALDI-HRMS, XRD, DSC, MIR and Raman spectroscopy
}

S. Bresson ${ }^{1}$, A. Lecuelle ${ }^{1}$, F. Bougrioua ${ }^{2}$ M. El Hadri ${ }^{3}$, V. Baeten ${ }^{4}$, M. Courty ${ }^{5}$, S. Pilard ${ }^{6}$, S. Rigaud $^{6}$, V. Faivre

${ }^{1}$ Institut Polytechnique UniLaSalle, Université d'Artois, ULR 7519, 19 Rue Pierre Waguet, BP 30313, 60026 Beauvais, France

${ }^{2}$ Departement de Physique, Faculté des sciences, Université de Picardie Jules Verne, 33 rue $S^{t}$ Leu 80039 Amiens cedex, France

${ }^{3}$ Laboratoire de Physique de la Matiere Condensée, Université Abdelmalek Essaadi, Tetouan, Morocco

${ }^{4}$ Walloon Agricultural Research Centre (CRA-W), Valorisation of Agricultural Products, Department, Quality and Authentication of Products Unit, 'Henseval Building', Chaussée de Namur 24, 5030 Gembloux, Belgium

${ }^{5}$ Laboratoire de Réactivité et Chimie des Solides, Université de Picardie Jules Verne, Hub de l'Energie, 15, rue Baudelocque, 80039 Amiens Cedex, France

${ }^{6}$ Plate-Forme Analytique, Université Picardie Jules Verne, 33 rue $S^{t}$ Leu, 80039 Amiens cedex, France

${ }^{7}$ Institut Galien Paris-Sud, Univ. Paris-Sud, Université Paris-Saclay, 5 rue JB Clément, 92296, Châtenay-Malabry, France

\begin{abstract}
A high quality chocolate requires not only a shiny surface, a crunchy and pleasant texture, but also a proper resistance to blooming. All these characteristics are influenced by the physical and chemical properties of the components, which are directly related to their crystalline structure. Some works found that the proportion of cocoa butter (CB), cocoa butter equivalent (CBE) and milk fatty acid (AMF) tend to strongly delay the blooming when mixing them. The goal of our research is to determine how the choice of adding CBE to the mixture delays chocolate blooming. ESI/MALDI-HRMS, X-ray, DSC, MIR and Raman investigations were used to analyze the structure features and the vibrational modes of $\mathrm{CB}$ and $\mathrm{CBE}$. The comparison of these experimental results between $\mathrm{CB}$ and $\mathrm{CBE}$ made it possible to highlight markers of differentiation between $\mathrm{CB}$ and $\mathrm{CBE}$ which seems to explain the impact of CBE in the chocolate blooming. Part of these triglycerides remains in form IV instead. The presence of the latter seems to be a key parameter that favors the transformation deceleration to the form VI, which is responsible for the fat bloom development.
\end{abstract}

KEYWORDS: Cocoa butter (CB), cocoa butter equivalent (CBE), MIR and Raman spectroscopies, X-ray diffraction, ESI/MALDI-HRMS, DSC. 


\section{Introduction :}

Fatty acids and triglycerides are key constituents of chocolate and chocolate products. Chocolate quality must have not only a shiny surface, a crunchy texture that is pleasant in the mouth, but also good resistance to heat and blooming. All these characteristics are influenced by the physicochemical properties of cocoa, directly linked to theacrystalline structure of these components. (Bresson et al, 2011).

The fatty blooming of chocolate is characterized by the loss of the initial gloss of its surface, giving it a more or less white appearance. In fact, a dull and whitish "film" then appears on the surface of the chocolate. It is called "fat" because, unlike sugar blooming, the surface seems "fat" to the touch. Blooming chocolate, therefore, not only affects the appearance of the product, but also the quality of its texture. This phenomenon is apparent from a structure change on the product surface. In fact, liquid triglycerides contained in the non-crystallized fat of chocolate migrate through the product to the surface of the product as chocolate is a porous material. The triglycerides (TG) then recrystallize on the surface. Then the formation of more or less large cones are observed. They are composed of triglyceride crystals reflecting light differently and consequently bringing about whitish appearance (Sonvaï and Rousseau, 2008 ; Briones and Aguilera, 2005 ; Hartel 1999). These cones are indicators of the micro-structural evolution of the product. Sonvaï and Rousseau observed these cones on the surface of a bloomed chocolate using an atomic force microscope (Sonvaï and Rousseau, 2008). Fat blooming comes from the fat contained in chocolate. Indeed, in a bloomed chocolate, one can observe the passage of polymorphic cocoa butter crystals from the $\mathrm{V}(\beta)$ form to the $\mathrm{VI}(\beta)$ form (Wille and Lutton, 1966; Sonvaï and Rousseau, 2008). Since this polymorphic form of cocoa butter crystals in solid chocolate is thermodynamically the most stable, fatty blooming of chocolate is inevitable. This problem is very costly for the chocolate industry and artisan chocolate makers, who cannot sell a product that does not look perfect. In a recent study commissioned by Swiss industry Nestlé (Reinke et al, 2015), it can be stated that while fat blooming is completely safe, but it costs the industry a fortune due to the scrapping of chocolates with altered appearance besides the consumer complaints. Food manufacturers therefore need to understand the process of fatty blooming of chocolate before production. There are three factors that can delay the phenomenon: storage, tempering and product composition. The storage temperature of the finished product must remain relatively low and 
constant. The blooming of chocolate develops simultaneously with the polymorphic evolution of cocoa butter, which is as much rapid and important as the storage temperature. When temperature is too high, a certain amount of the fatty part of the chocolate liquefies. This process leads to recrystallization in an unstable polymorphic form (IV ( $\left.\beta^{\prime}\right)$ form) when the temperature drops again. The product must therefore be stored at a constant temperature and below $30{ }^{\circ} \mathrm{C}$ (Sonvaï and Rousseau, 2008). To delay the appearance of cocoa butter crystals in VI $(\beta)$ form, the product must be subjected to the "tempering" process. This consists in exposing the chocolate to a certain temperature cycle so that the cocoa butter crystals could be found in V $(\beta)$ form, and not in VI $(\beta)$ form. The more the chocolate contains a maximum of V-form crystals and a minimum of VI-form crystals, the more the blooming will be delayed. The commercialized chocolates therefore initially contain V-form crystals. Finally, the composition of the chocolate influences the rate of blooming. If cocoa butter is responsible for the blooming, the other constituents, containing triglycerides equally, influence the speed of the phenomenon. These are fatty acids from milk and cocoa butter equivalent to CBE (Sonvaï and Rousseau, 2008). These authors have shown that the proportion of triglycerides in cocoa butter (CB), cocoa butter equivalent (CBE) and milk fatty acids (MF) in chocolate strongly speed up the blooming appearance. Products containing cocoa butter equivalent (CBE) take much longer time to bloom than products not containing it. "CB + MF" mass mixing, void of CBE, takes only two weeks before blooming, unlike thirty weeks (or fifteen times more) for " $\mathrm{CB}+\mathrm{MF}+\mathrm{CBE}$ " mixture. $\mathrm{CBE}$ therefore appears to delay very significantly the transition of the cocoa butter crystals in V-form to VI-form.

Another study, more recent, conducted by Bisvas et al. (Bisvas et al, 2017), also demonstrated that the presence of cocoa butter substitute (from palm oil, noted CBS) in the composition of a dark chocolate delayed the blooming of the product. Indeed, they showed that after two weeks of storage at $29^{\circ} \mathrm{C} \pm 1{ }^{\circ} \mathrm{C}$, a dark chocolate containing no cocoa butter substitute (CBS) bloomed, unlike a dark chocolate containing $20 \%$ CBS. However, their experiments also showed that chocolate containing only $5 \%$ CBS bloomed just like chocolate not containing CBS. The presence of CBS in dark chocolate therefore makes it possible to delay blooming, provided that its proportion in the product is sufficient. Da Silva et al (Da Silva, 2017) also concluded that when the chocolate was subjected to temperature cycling, the resistance of CBS and CBE to the formation of fat bloom became more evident.

In order to better understand the phenomenon of fatty blooming of chocolate, in this article, a complete comparative study between cocoa butter and cocoa butter equivalent is presented. The study will begin by determining the triglyceride composition between $\mathrm{CB}$ and $\mathrm{CBE}$ by 
electrospray (ESI) and Matrix Assisted Laser Desorption (MALDI) mass spectrometry ionization techniques using a high resolution (HRMS) Q-TOF instrument. It will continue with a study in X-ray diffraction as a function of temperature for CB and CBE and DSC study. To complete this structural study, investigations in -MIR and Raman spectroscopy will be presented for $\mathrm{CB}$ and $\mathrm{CBE}$.

\section{Materials and methods}

\subsection{Preparation and identification of Cocoa butter (CB), cocoa butter equivalent (CBE)}

Cocoa butter (CB) come from Ivory Coast. CB and CBE were both purchased from the industry Cadbury (Canada). In order to know the exact triglyceride composition of CB and CBE, mass spectrometry experiments were carried out by two different techniques: ESI-HRMS and MALDI-HRMS.

\section{ESI-HRMS Measurements}

Flow injections analysis (FIA) were performed using an ACQUITY UPLC H-Class chromatography system (Waters, Manchester, UK) coupled with a Synapt G2-Si Q-TOF hybrid quadrupole time-of-flight instrument (Waters, Manchester, UK), equipped with an electrospray (ESI) ionization source (Z-spray) and an additional sprayer for the reference compound (Lock Spray). The mobile phase was composed of $80 \%$ isopropanol, $15 \%$ acetonitrile, $5 \%$ water and $0.2 \%$ formic acid. The flow rate was set at $0.2 \mathrm{~mL} / \mathrm{min}$. One microliter of the $\mathrm{CB}$ and $\mathrm{CBE}$ solutions (15 mg in $1 \mathrm{~mL}$ of isopropanol/hexane 50/50, diluted 350 fold in the mobile phase) were injected. The source was operated in positive ion mode $\left(\mathrm{ESI}^{+}\right)$. Source and desolvation gas temperatures were kept at 120 and $400{ }^{\circ} \mathrm{C}$, respectively. Nitrogen $(>99.5 \%)$ was used as drying and cone gas at flow rates of 600 and $50 \mathrm{~L} / \mathrm{h}$, respectively. The capillary voltage was + $3 \mathrm{kV}$, the cone voltage $20 \mathrm{~V}$ and the source offset $20 \mathrm{~V}$. Calibration of the instrument was performed using the ions produced by a sodium formate solution $(10 \mathrm{mM} \mathrm{NaOH}$ in isopropanol/water/formic acid 49.9/49.9/0.2). For accurate mass measurements, an internal lock mass correction using the $[\mathrm{M}+\mathrm{H}]^{+}$ion $(\mathrm{m} / \mathrm{z} 556.2771 \mathrm{u})$ of a leucine encephalin solution ( $1 \mathrm{ng} / \mu \mathrm{L}$ in water/acetonitrile/formic acid 50/49.9/0.1) was applied. The TOF acquisition mass range was 50-2000 u and spectra were recorded at 0.2 s/scan using the resolution mode, providing an average resolving power of 30000 (FWHM). Data acquisition and processing were performed with MassLynx software (V4.1, Waters). 


\section{MALDI-HRMS Measurements}

MALDI-TOF experiments were performed on the SYNAPT G2-Si equipped with an intermediate pressure (IP) MALDI ionization source. The source was operated with a $2.5 \mathrm{KHz}$ solid state UV laser system $(\lambda=355 \mathrm{~nm})$. Data were recorded in positive ion mode $\left(\mathrm{MALDI}^{+}\right)$. Mass calibration from 50 to $4050 \mathrm{u}$ was carried out using a DCTB/CSI3 mixture at a 2/1 molar ratio in THF. The scan range was 50-2050 u at $1 \mathrm{~s} / \mathrm{scan}$. The TOF was operated in the sensitivity mode, providing an average resolving power of 20,000 (FWHM). The source parameters were as follow: sample plate, $20 \mathrm{~V}$; extraction, $20 \mathrm{~V}$; hexapole, $10 \mathrm{~V}$ and aperture, $5 \mathrm{~V}$. CB and CBE samples were dissolved in THF $(25 \mathrm{mg} / \mathrm{mL})$ and the MALDI matrix used in this study was DCTB $(25 \mathrm{mg} / \mathrm{mL}$ in THF). The MALDI spots were prepared according to the sandwich method, as follows: MALDI matrix $(1 \mu \mathrm{L})$ was firstly deposited on the mirror polished stainless steel MALDI target (Waters 405010856, $8 \mathrm{~cm}$ x $12 \mathrm{~cm}$, 96 well), then sample (1 $\mu \mathrm{L})$ was applied, followed by a last layer of matrix $(1 \mu \mathrm{L})$. As for ESI data acquisition and processing were performed with MassLynx software (V4.1, Waters).

\subsection{X-ray diffraction (XRD)}

XRD patterns were continuously recorded in transmission mode using quartz capillaries (1.5 mm diameter, W. Müller, Berlin, Germany) and the X-ray generator was a long line focus sealed

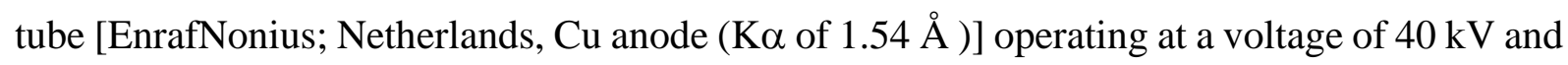
a current of $20 \mathrm{~mA}$. Two gas-filled linear detectors (1024 channels each, filled with an argonethane mixture) were used to collect the data. With the settings used, scattering $q$ vectors ranging from 0.08 to $0.52 \AA^{-1}$ and from 1.00 to $2.00 \AA^{-1}$ were evaluated. The scattering vector was defined as $q=4 \pi \sin (\theta) / \lambda$ where $2 \theta$ is the scattering angle. From this scattering vector, it was possible to calculate the distances via $q=2 \pi / \mathrm{d}$. Calibration of the detectors was carried out using the XRD pattern of the $2 \mathrm{~L} \beta$ form of pure tristearin $(4.61,3.84$ and $3.70 \pm 0.01 \AA$ and $44.97 \pm 0.05 \AA)$ and that of the silver behenate $(58.38 \pm 0.01 \AA)$. Microcalix, a microcalorimeter specially designed for installation in an X-ray beam was used as a thermostated sample holder. When needed, peak spectral decomposition was performed using Origin 5.0 software (OriginLab Corporation, Northampton, MA, USA).

\subsection{Differential scanning calorimetry (DSC)}

The DSC experiments were carried out on a Netzsch DSC 204F1 heat flux differential calorimeter at a heating rate of $2^{\circ} \mathrm{C} / \mathrm{min}$ under a constant argon flow with $200 \mathrm{~mL} / \mathrm{min}$. Samples were weighed in aluminum sample pans covered with a pierced lid. An empty aluminum sample 
pan with a pierced lid was used as a reference. Three temperatures could be measured: $T_{\text {onset }}$, $\mathrm{T}_{\max }$ and $\mathrm{T}_{\text {offset }}$, which correspond respectively to the beginning, the top and the end of thermal events.

\subsection{MIR spectroscopy}

The measurements were all carried out at the Walloon Agricultural Research Center CRA$\mathrm{W}$, in Belgium. The apparatus consists of a FT-MIR Vertex 70 spectrometer (Brukeroptics, Ettlingen, Germany) equipped with a Golden Gate ATR (Attenuated Total Reflectance). This ATR consists of a monolithic diamond crystal. The incident beam contains radiations of 4000 à $600 \mathrm{~cm}^{-1}$, or which corresponds to the medium infrared. The incident light penetrates the sample to a depth of $7 \mu \mathrm{m}$ maximum, after having passed through the diamond. The reflected beam emerges through the diamond before reaching the detector. The spectral resolution was set at $1 \mathrm{~cm}^{-1}$ and the number of co-added spectra was set to 128 scans. The measurements are carried out at room temperature. Spectra of the ambient air was used as background.

\subsection{Raman spectroscopy}

The measurements were carried out at the Walloon Agricultural Research Center (CRA-W), Belgium. FT-RAMAN spectra were acquired using a Vertex 70-RAM II Bruker FT-RAMAN spectrometer (Brukeroptics, Ettlingen, Germany). This instrument is equipped with an $\mathrm{Nd}$ : YAG laser (yttrium aluminium garnet crystal doped with triply ionised neodymium) with an incident laser wavelength at $1064 \mathrm{~nm}\left(9398.5 \mathrm{~cm}^{-1}\right)$. The RAM II spectrometer is equipped with a liquid-nitrogen cooled Ge detector. FT-RAMAN spectra [ $4000-45 \mathrm{~cm}^{-1}$ ] were collected with a resolution of $1 \mathrm{~cm}^{-1}$ by co-adding 128 scans for each spectrum at room temperature.

\section{Results and discussion}

\subsection{Identification of the main triglycerides of $C B$ and $C B E$}

In order to determine the triglyceride composition of complex mixtures such as cacao butters, two mass spectrometric techniques: matrix assisted laser desorption ionization (MALDI) and electrospray ionization (ESI) were investigated. Indeed, ESI and MALDI are complementary due to the possible biases of the two techniques during the sample preparation steps and the ionization process (solubility differences, ion suppression...). 
We present in Fig.1 the MALDI ${ }^{+}$mass spectra for CB and CBE.
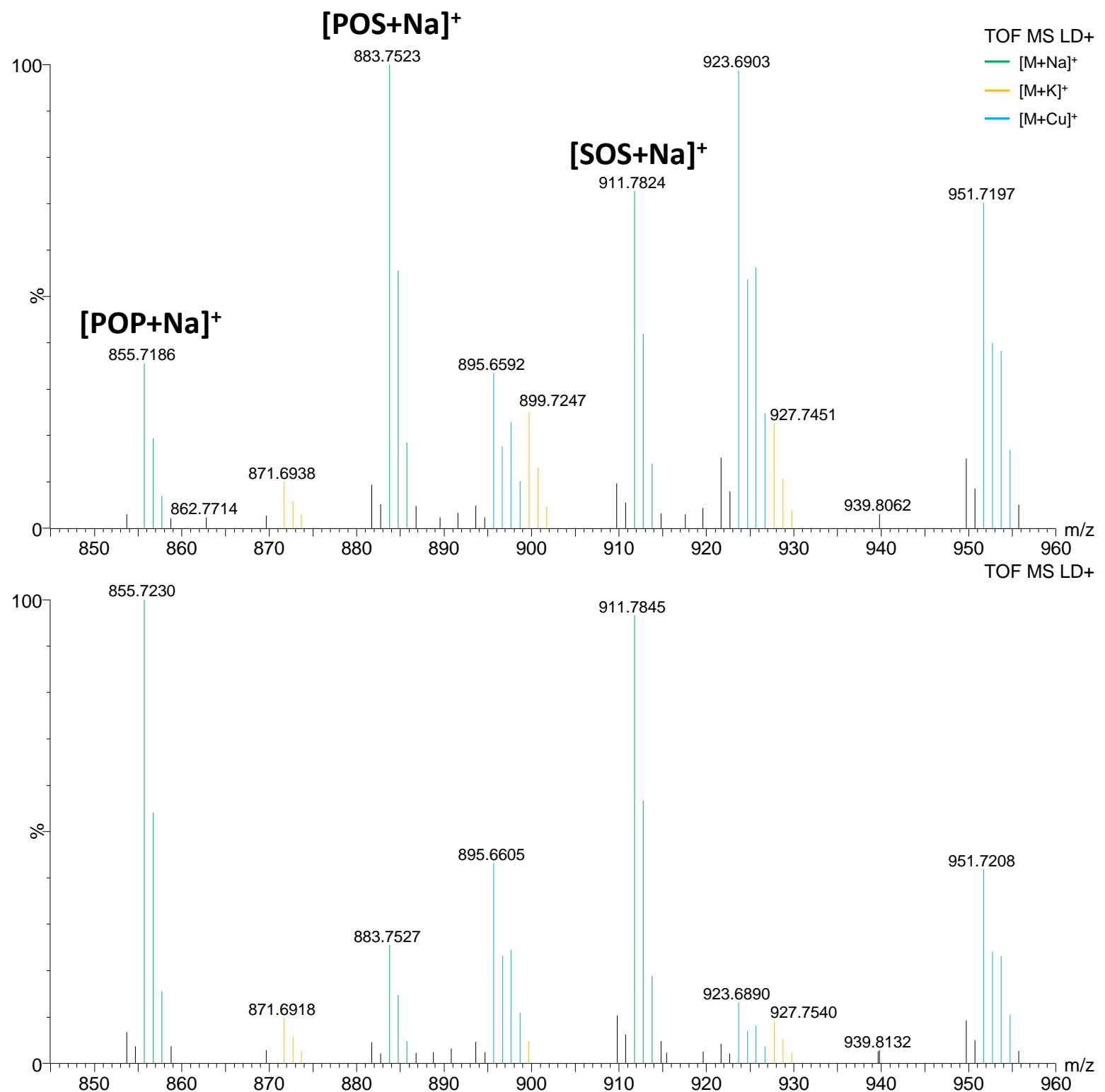

Fig. 1 : CB (top) and CBE (bottom) triglycerides mass region (845-960 u) obtained from MALDI ionization.

In the mass range corresponding to triglyceride signals $(845-960 \mathrm{u})$, the difference between the two butters resides in the respective relative intensity of the $[\mathrm{M}+\mathrm{Na}]^{+}$ions at $\mathrm{m} / \mathrm{z} 855(1,3$ dipalmitoyl-2-oleoylglycerol: POP), m/z 883 (1-palmitoyl-2-oleoyl-3-stearoylglycerol: POS) and $\mathrm{m} / \mathrm{z} 911$ (1,3 distearoyl-2-oleoylglycerol: SOS), which correspond to triglycerides with fatty acids of different length (mass difference of $28 \mathrm{u}$ corresponding to $\mathrm{CH}_{2}-\mathrm{CH}_{2}$ ). The same 
distribution is observed for $[\mathrm{M}+\mathrm{K}]^{+}$and $[\mathrm{M}+\mathrm{Cu}]^{+}$ions as depicted Fig.1. The main difference in the spectra is due to POS which is more abundant in CB than in CBE.

The $\mathrm{ESI}^{+}$analysis (Fig.S1) shows the same distribution profile for the triglyceride $[\mathrm{M}+\mathrm{Na}]^{+}$ ions, providing reliable results (Table 1). From these observations, we can conclude that our $\mathrm{CB}$ and $\mathrm{CBE}$ samples are identical with respect to the triglyceride content, but regarding the three triglycerides detected (POS, SOS and POP) the proportions are different: in CB, POS dominates in quantity compared to the other two (practically $50 \%$ of the total). In contrast, POP plays this role (practically $46 \%$ of the total) with a slight increase of SOS in CBE.

Table 1: Comparison of POS, SOS and POP respective intensity for $C B$ and $C B E$ according to the type of mass spectrometry ionization technique (data presented for the following $\mathrm{m} / \mathrm{z}$ : POS (883), SOS (911) and POP (855), corresponding to the $[\mathrm{M}+\mathrm{Na}]^{+}$ions).

\begin{tabular}{|c|c|c|c|}
\hline MS experiments & Triglycerides & Intensity & \% from (POS+SOS+POP) \\
\hline $\boldsymbol{C B}$ & $P O S$ & $1.25 \mathrm{E}+07$ & $\mathbf{4 8} \%$ \\
$M A L D I^{+}-H R M S$ & $S O S$ & $8.97 \mathrm{E}+06$ & $34 \%$ \\
& $P O P$ & $4.57 \mathrm{E}+06$ & $\mathbf{1 8} \%$ \\
\hline $\boldsymbol{C B}$ & $P O S$ & $3.56 \mathrm{E}+07$ & $\mathbf{4 9} \%$ \\
$E S I^{+}-H R M S$ & $S O S$ & $2.44 \mathrm{E}+07$ & $33 \%$ \\
& $P O P$ & $1.34 \mathrm{E}+07$ & $\mathbf{1 8} \%$ \\
\hline $\boldsymbol{C B E}$ & $P O S$ & $1.92 \mathrm{E}+06$ & $\mathbf{1 2} \%$ \\
$M A L D I^{+}-H R M S$ & $S O S$ & $6.95 \mathrm{E}+06$ & $43 \%$ \\
& $P O P$ & $7.13 \mathrm{E}+06$ & $\mathbf{4 5} \%$ \\
\hline $\boldsymbol{C B E}$ & $P O S$ & $7.00 \mathrm{E}+06$ & $\mathbf{1 2} \%$ \\
$E S I^{+}-H R M S$ & $S O S$ & $2.56 \mathrm{E}+07$ & $43 \%$ \\
& $P O P$ & $2.75 \mathrm{E}+07$ & $\mathbf{4 6} \%$ \\
\hline
\end{tabular}

\subsection{Polymorphic discrimination}

\subsubsection{Cocoa butter (CB)}

It is known that each triglyceride found in cocoa butter can exhibit several crystalline forms (I, II, III, IV, V and VI). X-ray diffraction is commonly used to study the polymorphic structures of triglycerides. Bresson and Rousseau measured long and short spacings for each polymorphic forms of coca butter (Bresson et al, 2011).

Since the sample of cocoa butter experiments is six years old, TG should be in form VI at room temperature since it is the most stable form. Fig.2a) exhibits the intensity of both SAXS (Small Angle X-ray Scattering) and WAXS (Wide Angle X-ray Scattering) configurations at room temperature. 

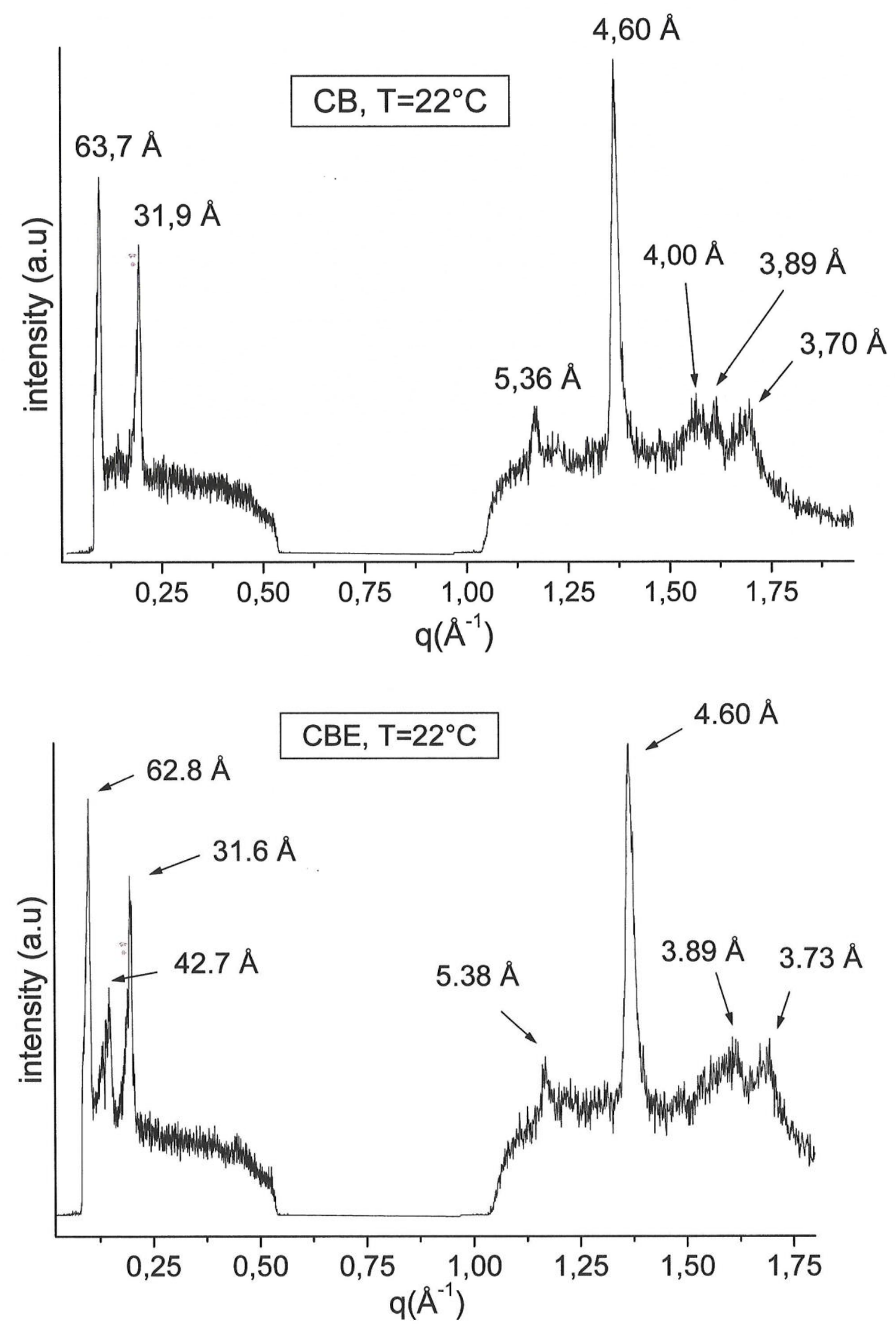

Fig. 2: Xray diffractograms of both SAXS (Small Angle X-ray Scattering) and WAXS (Wide Angle X-ray Scattering) configurations at room temperature for CB (a) and CBE (b). 
Peaks at small angles are assigned to long d-spacings, reflecting the lamellar structure of TG; peaks at wide angle corresponds to short d-spacing, defining distances between chains of TG. The small angles XRD pattern at room temperature presents two intense and well defined peaks at $63.7 \AA\left(\mathrm{q}=0.099 \AA^{-1}\right)$ and at $31.9 \AA\left(\mathrm{q}=0.197 \AA^{-1}\right)$. According to the literature (Bresson et $a l, 2011)$, the long d-spacings values of $63.7 \AA$ and $31.9 \AA$ correspond to the first and the second ordered respectively of the same lamellar organization 3L (trilayered stacking). Those peaks are labeled as $3 L_{001}$ and $3 L_{002}$ respectively. Especially, POS, SOS and POP have respectively in the $\beta$ form the long d-spacings values of $63.7 \AA$ (Ghazani and Marangoni 2018), $65.0 \AA$ (Sato et $a l, 1989$ ) and $62.0 \AA$ (Gibon et al, 1986). Four peaks are observed at wide angles corresponding to short d-spacings at $5.63 \AA$ ( $\left.q=1.11 \AA^{-1}\right), 4.60 \AA$ ( $\left.q=1.37 \AA^{-1}\right), 3.89 \AA$ ( $q=1.62$ $\left.\AA^{-1}\right)$ and $3.70 \AA\left(q=1.70 \AA^{-1}\right)$. The most intense peak is the one at $4.60 \AA$ and can be assigned to the crystallization of the TG in the $\beta$ form. According to the literature, the weaker peaks at $3.89 \AA$ and $3.70 \AA$ can be attributed to the $\beta$ form too. It can be noticed that the peak at $5.63 \AA$ was identified as a marker of the $\beta_{1}$ form of POS by Saeed M. Ghazani et al (Ghazani and Marangoni, 2019) and of a mixture of the L-2 and L-3 $\beta$ ' forms of POP by V. Gibon et al (Gibon et al, 1986). The trilayered stacking organization in a $\beta$ form at those long and short spacings values suggest that the TG in the sample at room temperature are either in form V either in form VI. To distinguish form $\mathrm{V}$ and form VI, the melting onset temperature is a useful tool. The differential scanning calorimetry will be necessary. Nevertheless, according to the age of the sample, TG of CB should be in form VI at room temperature.

Next, the sample has been heated to liquid state to erase its polymorphic history. Then, it has been cooled from $50^{\circ} \mathrm{C}$ to $-7^{\circ} \mathrm{C}$ at $1{ }^{\circ} \mathrm{C} / \mathrm{min}$ to study the crystallization of the TG. The structural evolution with temperature of the sample was acquired for both SAXS and WAXS configurations (see Figs S2).

When cooling down several peaks grow up. A strong peak, with two components: $51.5 \AA$ $\left(\mathrm{q}=0.122 \AA^{-1}\right)$ and $48.4 \AA\left(\mathrm{q}=0.130 \AA^{-1}\right)$; and a small one at $16.3 \AA\left(\mathrm{q}=0.385 \AA^{-1}\right)$, can be observed at small angles at $\mathrm{T}=13^{\circ} \mathrm{C}$. According to the literature, the two components at 51.5 $\AA$ and $48.4 \AA$ are both related to a first order of a bilayered stacking structure $\left(2 L_{001}\right)$. The existence of two peaks associated to the same order of the same organization means there is TG in bilayered structure with two different lateral packing. The peak at $16.3 \AA$ is related to the third order of the same structure $\left(2 L_{003}\right)$, corresponding to one or both lateral packing (16.3 51.5/3 and 16.3 48.4/3). Bresson et al are defined a cocoa butter polymorph 
isolation protocol : for form II, $\mathrm{CB}$ was cooled to $0^{\circ} \mathrm{C}$ at $2^{\circ} \mathrm{C} / \mathrm{min}$ from the $60^{\circ} \mathrm{C}$ melt and held $60 \mathrm{~min}$; Form III was prepared by cooling $\mathrm{CB}$ to $14^{\circ} \mathrm{C}$ at $2^{\circ} \mathrm{C} / \mathrm{min}$ from $60^{\circ} \mathrm{C}$ and crystallized $60 \mathrm{~min}$; and for the preparation of form IV, CB was cooled to $22^{\circ} \mathrm{C}$ at $10^{\circ} \mathrm{CC} / \mathrm{min}$ from the $60^{\circ} \mathrm{C}$ melt and held isothermally for $120 \mathrm{~min}$ (Bresson et al, 2011). They noticed that the long spacings for form II (2L) and form III (2L) have an important peak at $49.3 \AA$ and $48.5 \AA$ respectively. At $\mathrm{T}=13^{\circ} \mathrm{C}$, the Xray cooling protocol reveals the two polymorphic forms: form II and form III approximately in the same proportion (we observe two peaks well defined at $\mathrm{T}$ $=13^{\circ} \mathrm{C}$. At $\mathrm{T}=-7^{\circ} \mathrm{C}$, we observe one defined peak at $48.5 \AA$ with a shoulder at $51.5 \AA$ (see Fig. S2). This seems that TG are more in Form III than in Form II. The wide angles XRD pattern at $-7^{\circ} \mathrm{C}$ presents one peak at $4.20 \AA\left(\mathrm{q}=1.496 \AA^{-1}\right)$, which corresponds to the hexagonal $\alpha$ lateral packing. According to the literature, no form is associated to a $2 \mathrm{~L} \beta$ structure. Thus, we could assume that TG could be either in a $\alpha$ form either in a $\beta^{\prime}$ form. Peaks associated to the $\beta$ ' form are probably present in the wide angles XRD pattern but with very weak intensities. Since the distances separating the chains in $\alpha$ form are longer than in $\beta^{\prime}$ form, the peak at $51.5 \AA$ could be associated to the $2 \mathrm{~L} \alpha$ structure and the peak at $48.4 \AA$ to the $2 \mathrm{~L} \beta$ ' structure. In summary, TG in $\mathrm{CB}$ after crystallization at $2^{\circ} \mathrm{C} / \mathrm{min}$ are either in $2 \mathrm{~L} \alpha$ form either in $2 \mathrm{~L} \beta$ ' form at $-7^{\circ} \mathrm{C}$.

\subsubsection{Cocoa Butter Equivalent (CBE)}

Since cocoa butter and cocoa butter equivalent have the same composition, all TG of CBE should be in form VI as well as TG of $\mathrm{CB}$ at room temperature according the previous studies. Small and wide angles pattern of CBE at room temperature are presented in Fig.2b). Three peaks at $62.8 \AA\left(\mathrm{q}=0.100 \AA^{-1}\right), 42.7 \AA\left(\mathrm{q}=0.147 \AA^{-1}\right)$ and at $31.6 \AA\left(\mathrm{q}=0.199 \AA^{-1}\right)$ are presents as long d-spacings. It can be noticed that the peaks at $62.8 \AA$ and at $31.6 \AA$ are very closed to the values of long d-spacings found in CB X-ray diffraction study, so the assignment is the same: $3 L_{001}$ and $3 L_{002}$ respectively. However, the peak at $42.7 \AA$ was not present in the small angle XRD pattern for CB. According to the literature (Bresson et al, 2011) the long dspacings values of $42.7 \AA$ corresponds to the first order of the bilayered organization $\left(2 L_{001}\right)$ for TG in the $\beta$ ' form. In this form, POS, SOS and POP have respectively the long d-spacings values of $68.0 \AA, 70 \AA$ (Sato et al, 1989; Arishima et al, 1991) and 45 (Gibon et al, 1986). From the ESI-HRMS experiments, we have noted that between $\mathrm{CB}$ and CBE, POS and POP had reversed roles: for $\mathrm{CB}, \mathrm{POS}$ is predominant in quantity while for $\mathrm{CBE}$, it is POP. At room temperature, the Xray diffractogram in SAXS configuration reveals a significant number of POP in the $\beta$ ' form for CBE. 
Four peaks are observed at wide angles: an intense one at $4.60 \AA$ ( $\left.\mathrm{q}=1.37 \AA^{-1}\right)$ and three with small intensities at $5.38 \AA\left(\mathrm{q}=1.17 \AA^{-1}\right), 3.89 \AA\left(\mathrm{q}=1.62 \AA^{-1}\right)$ and $3.73 \AA$ ( $\left.\mathrm{q}=1.69 \AA^{-1}\right)$. They are related to the $\beta$ form as well as the TG in $\mathrm{CB}$, except the peak at $5.38 \AA$ which can assign to $\beta$ and $\beta$ 'forms of TG.

Thus, some TG in CBE at room temperature are in $3 \mathrm{~L} \beta$ form as well as the TG in $\mathrm{CB}$, but others TG in CBE are in a 2L $\beta$ ' organization (form IV).

As well as $\mathrm{CB}$, the sample of $\mathrm{CBE}$ has been cooled from $50^{\circ} \mathrm{C}$ to $-8^{\circ} \mathrm{C}$ at $1{ }^{\circ} \mathrm{C} / \mathrm{min}$, inducing structural evolution of the sample with temperature acquired for both SAXS and WAXS configurations (See Figs. S2).

The small angles XRD pattern at $-8^{\circ} \mathrm{C}$ presents two peaks. The first one is strong and has two components at $51.5 \AA\left(\mathrm{q}=0.122 \AA^{-1}\right)$ and at $48.4 \AA\left(\mathrm{q}=0.130 \AA^{-1}\right)$; and the second one at 16.2 $\AA\left(q=0.388 \AA^{-1}\right)$ is weak. The wide angles XRD pattern exhibits one peak at $4.20 \AA$ ( $q=1.496$ $\AA^{-1}$ ). Those values are similar than the ones found for CB. The discussion is the same as well as the assignment of the peaks. Thus, TG in CBE after crystallization at $2^{\circ} \mathrm{C} / \mathrm{min}$ are either in $2 \mathrm{~L} \alpha$ form either in $2 \mathrm{~L} \beta^{\prime}$ form at $-8^{\circ} \mathrm{C}$, as well as TG in $\mathrm{CB}$. But, it is not possible for us with these results to know at $-7^{\circ} \mathrm{C}$ if the triglycerides are in form III or in form IV. The CB and CBE DSC studies will answer this question.

Table S3 summarizes the structures and values of the diffraction peaks of samples at room temperature.

$\mathrm{X}$-ray diffraction showed that CB sample was in polymorphic structure VI at room temperature. This was expected considering the advanced age of cocoa butter. CBE sample is the same age as $\mathrm{CB}$ sample. It is known that $\mathrm{CB}$ and $\mathrm{CBE}$ have the same $\mathrm{TG}$ composition, but TGs come from sources. It could therefore be expected that all TGs present in CBE would also exist in VI form. This is shown by the results in ESI- and MALDI -HRMS but with an inversion in quantity between POS and POP.

However, X-ray diffraction showed that some TGs of CBE were not found in form VI $\left(3 L \beta_{2}\right)$ but found in form $\operatorname{IV}\left(2 L \beta_{2}^{\prime}\right)$. This constitutes microscopic evidence that CBE slows the blooming of milk chocolate. In fact, form VI, which is at the origin of chocolate blooming, is not the only form present for $\mathrm{CBE}$ at room temperature. 
In addition, the structural study by X-ray diffraction coupled with a thermal study by DSC demonstrates that the triglycerides of $\mathrm{CB}$ and $\mathrm{CBE}$ coexist in two polymorphic forms around $-7^{\circ} \mathrm{C}$ after crystallization at $1^{\circ} \mathrm{C} \cdot \mathrm{min}^{-1}: 2 L \alpha$, and $2 L \beta^{\prime}$.

Table S4 summarizes the structures and the values of the diffraction peaks of samples during their crystallization.

\subsection{Differential scanning calorimetry}

\subsubsection{Cocoa Butter $(C B)$}

XRD study of CB at room temperature could not distinguish form V to form VI. Since melting onset temperature is different for each polymorphic structure, it is interesting to study the thermal behavior of $\mathrm{CB}$ for melting from room temperature to $60^{\circ} \mathrm{C}$ at $2^{\circ} \mathrm{C} / \mathrm{min}$. In Fig $3 \mathrm{a}$ ), DSC curve in temperature range $\left[25^{\circ} \mathrm{C} ; 50^{\circ} \mathrm{C}\right]$ gives endothermic behavior of the sample. The melting onset temperature is $T_{\text {onset }}=33^{\circ} \mathrm{C}$. According to the literature, it corresponds to form VI (Bresson et al, 2011). From Fig. 3a), the total energy absorbed by the sample can be calculated from the area between the curve and the baseline: it is estimated at $111 \mathrm{~J} / \mathrm{g}$.
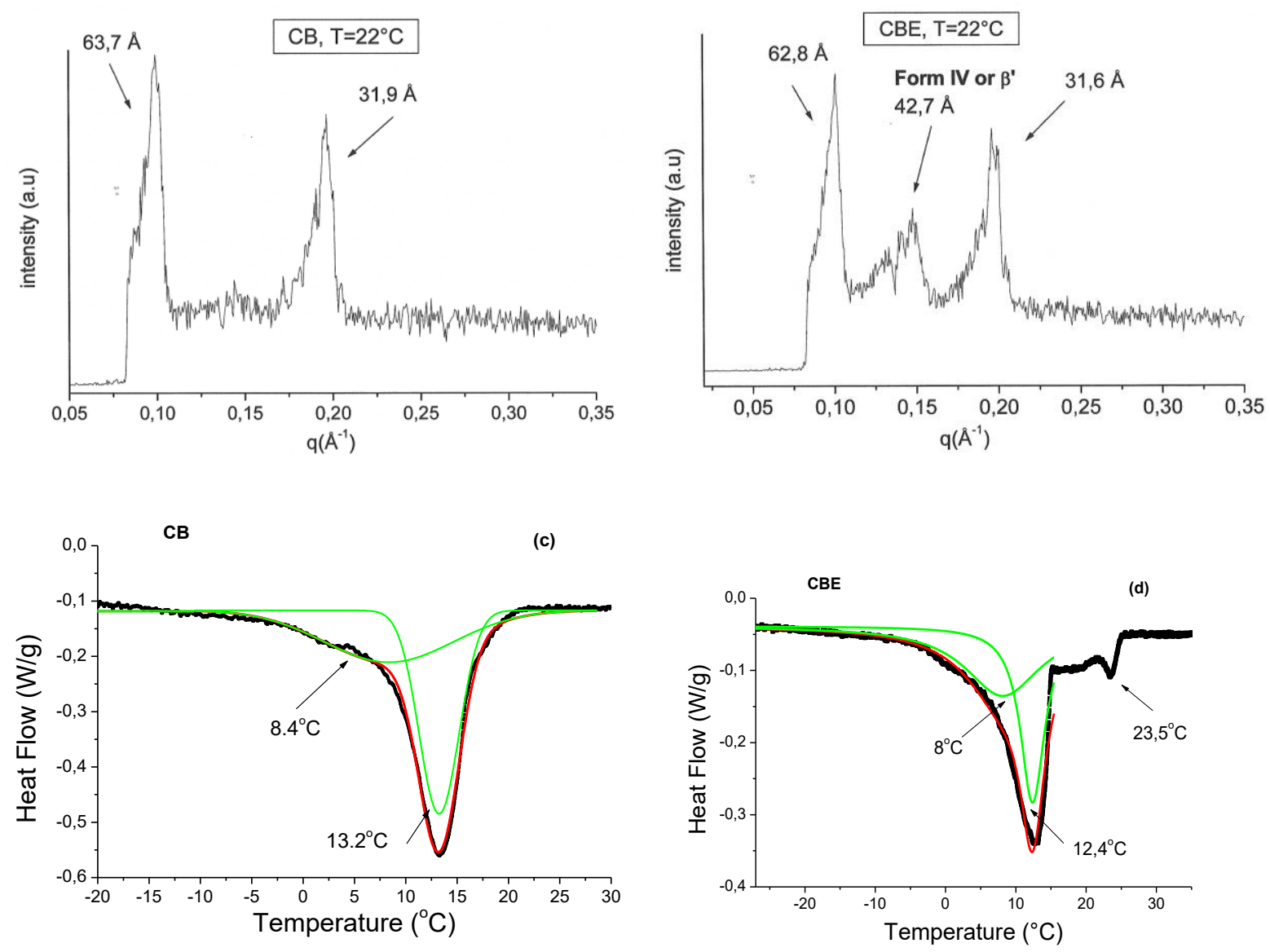

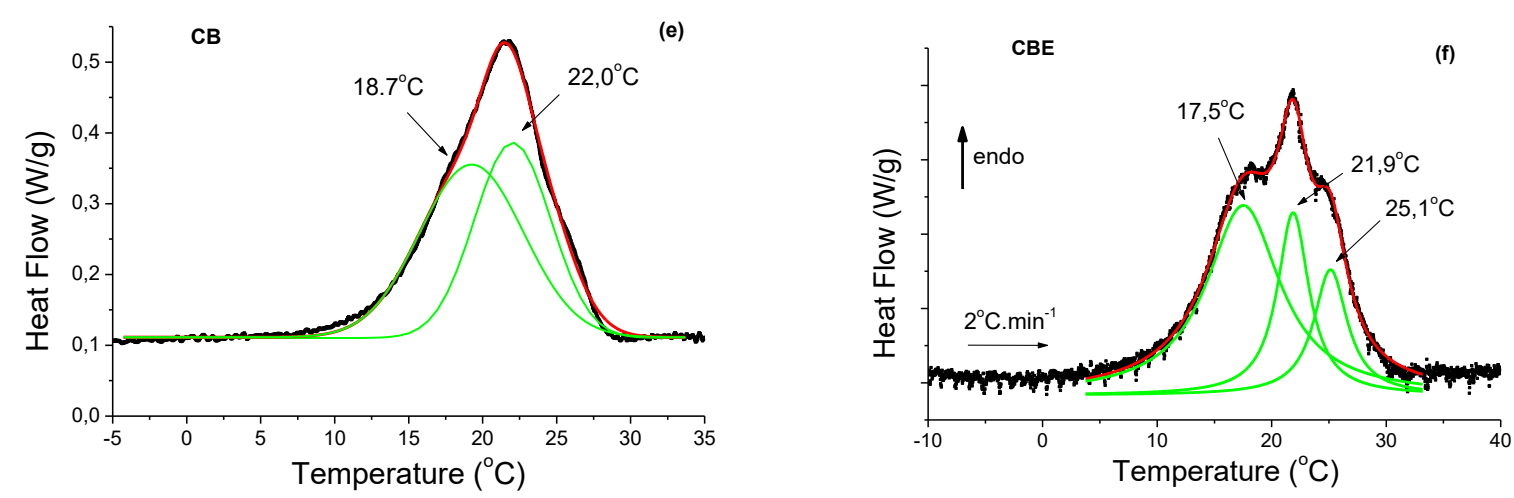

Fig. 3: DSC curves during the first melting of CB (a) and CBE (b) from room temperature $\mathrm{T}=24{ }^{\circ} \mathrm{C}$ to $60{ }^{\circ} \mathrm{C}$ at a speed of $2{ }^{\circ} \mathrm{C} \cdot \mathrm{min}^{-1}$, during crystallization of the sample of cocoa butter (CB) (c) and $\mathrm{CBE}$ (d) from $60{ }^{\circ} \mathrm{C}$ to $-100{ }^{\circ} \mathrm{C}$ at a speed of 2 ${ }^{o} \mathrm{C}_{\text {min }}{ }^{-1}$, and during the second melting of CB (e) and CBE (f). In figures (c, d, e and f)), the components of Gaussian functions are in green, the resultant in red, and the data in black.

Then, the sample was cooled from $60^{\circ} \mathrm{C}$ to $-100^{\circ} \mathrm{C}$ at $2^{\circ} \mathrm{C} / \mathrm{min}$. A fit by Gaussian functions of DSC curve is proposed in fig 3c). Two components suggest the existence of two exothermic events at $T_{\max }=13.2^{\circ} \mathrm{C}$ and $T_{\max }=8.4^{\circ} \mathrm{C}$. Finally, the sample of CB was heated from $-100^{\circ} \mathrm{C}$ to $60^{\circ} \mathrm{C}$ at $2^{\circ} \mathrm{C} / \mathrm{min}$. DSC curve is fitted as well. Fig 3e) This curve shows two endothermic events at $T_{\max }=18.7 \mathrm{C}$ and $T_{\max }=22.0^{\circ} \mathrm{C}$. According to the previous XRD study, TG in $\mathrm{CB}$ at $-7^{\circ} \mathrm{C}$ were crystallized either in $2 \mathrm{~L} \alpha$ structure or in $2 \mathrm{~L} \beta$ ' structure. Bresson et al measured the melting onset temperature of each polymorphic form of CB (Bresson et al, 2011). The $2 \mathrm{~L} \alpha$ structure, which can only correspond to the form II, has $T_{\text {onset }} \sim 17^{\circ} \mathrm{C}$, whereas the $2 \mathrm{~L} \beta$ ' structure can be associated to the form III $\left(T_{\text {onset }} \sim 20^{\circ} \mathrm{C}\right)$ or IV $\left(T_{\text {onset }} \sim 26^{\circ} \mathrm{C}\right)$. Thus, we can conclude that the two events correspond to two groups of TG: $2 \mathrm{~L} \alpha$ (form II), $2 \mathrm{~L} \beta^{\prime}{ }_{1}$ (form III). The first group of TG to crystallize is the last to melt. So, the polymorphic structures of $\mathrm{CB}$ at room temperature, when cooling and when heating can then be summarized as follow:

At $22^{\circ} \mathrm{C}: 3 \mathrm{~L} \beta(\mathrm{VI}) \stackrel{\text { heating }}{\longrightarrow}$ liquid

liquid $\stackrel{\text { cooling to }-8^{\circ} \mathrm{C}}{\longrightarrow} 2 \mathrm{~L} \beta^{\prime}{ }_{1}$ (III) from $13.2^{\circ} \mathrm{C} \stackrel{\text { heating }}{\longrightarrow}$ liquid from $22.0^{\circ} \mathrm{C}$

liquid $\stackrel{\text { cooling to }-8^{\circ} \mathrm{C}}{\longrightarrow} 2 \mathrm{~L} \alpha$ (II) from $8.4^{\circ} \mathrm{C} \stackrel{\text { heating }}{\longrightarrow}$ liquid from $18.7^{\circ} \mathrm{C}$

\subsubsection{Cocoa butter equivalent (CBE)}


In Fig 3b), DSC curve gives endothermic behavior for the first melting at room temperature. It confirms that the majority of TG of CBE at room temperature was in form VI. From Fig. 3b), the total energy absorbed by the sample can be calculated from the area between the curve and the baseline: it is estimated at $135 \mathrm{~J} / \mathrm{g}$. This energy value is more important than for CB. This phenomenon seems to indicate that all triglycerides are not only in form VI.

Then, the sample was cooled from $60^{\circ} \mathrm{C}$ to $-100^{\circ} \mathrm{C}$ at $2^{\circ} \mathrm{C} / \mathrm{min}$. A fit by Gaussian functions of DSC curve is proposed in Fig 3d). There are three exothermic events at $T_{\max }=23.0^{\circ} \mathrm{C}, T_{\max }=$ $12.4^{\circ} \mathrm{C}$ and $T_{\max }=8.0^{\circ} \mathrm{C}$. In a further step, the sample of $\mathrm{CBE}$ was heated from $-100^{\circ} \mathrm{C}$ to $60^{\circ} \mathrm{C}$ at $2{ }^{\circ} \mathrm{C} / \mathrm{min}$. DSC curve is fitted as well (Fig. 3f)). There are three endothermic events at $T_{\text {max }}=17.5^{\circ} \mathrm{C}, T_{\max }=21.9^{\circ} \mathrm{C}$ and $T_{\max }=25.1^{\circ} \mathrm{C}$. The results are different from CB results. We observe a new component for DSC curves: a crystallization at $T_{\max }=23.0^{\circ} \mathrm{C}$ corresponding to the crystallization of Form IV, followed by a melting point at $T_{\max }=25.1^{\circ} \mathrm{C}$. This difference in thermic behavior seems to be linked to the greater presence of POP triglycerides in $\mathrm{CBE}$ compared to $\mathrm{CB}$. So, the polymorphic structures of $\mathrm{CBE}$ at room temperature, when cooling and heating, can then be summarized as follow:

At $22^{\circ} \mathrm{C}: 3 \mathrm{~L} \beta(\mathrm{VI})$ and $2 \mathrm{~L} \beta$ ' (IV) $\stackrel{\text { heating }}{\longrightarrow}$ liquid

liquid $\stackrel{\text { cooling to }-8^{\circ} \mathrm{C}}{\longrightarrow} 2 \mathrm{~L}{\beta^{\prime}}_{2}(\mathrm{IV})$ from $23^{\circ} \mathrm{C} \stackrel{\text { heating }}{\longrightarrow}$ liquid from $25.1^{\circ} \mathrm{C}$

liquid $\stackrel{\text { cooling to- } 8^{\circ} \mathrm{C}}{\longrightarrow} 2 \mathrm{~L} \beta^{\prime}{ }_{1}$ (III) from $12.4^{\circ} \mathrm{C} \stackrel{\text { heating }}{\longrightarrow}$ liquid from $21.9^{\circ} \mathrm{C}$

liquid $\stackrel{\text { cooling to }-8^{\circ} \mathrm{C}}{\longrightarrow} 2 \mathrm{~L} \alpha$ (II) from $8^{\circ} \mathrm{C} \stackrel{\text { heating }}{\longrightarrow}$ liquid from $17.5^{\circ} \mathrm{C}$

\subsection{ATR/FTIR investigations}

\subsubsection{Cocoa butter (CB)}

The MIR spectrum of cocoa butter at room temperature $\left(T=22^{\circ} C\right)$ is shown in Fig. 4a) in the spectral region $3050-500 \mathrm{~cm}^{-1}$.

Different regions can be seen on the spectrum:

- the spectral region $1800-1700 \mathrm{~cm}^{-1}$ corresponding to the ester carbonyl stretching region);

- the spectral region $3200-2700 \mathrm{~cm}^{-1}$ corresponding to the $C-H$ stretching mode.

- the spectral region $1500-600 \mathrm{~cm}^{-1}$ corresponding to the fingerprint of the sample. This area shows many vibrations of elongation and deformation. Very rich and very complex, the region is characteristic for each molecule present in the sample. 
(a) $\mathrm{CB}$ at room temperature
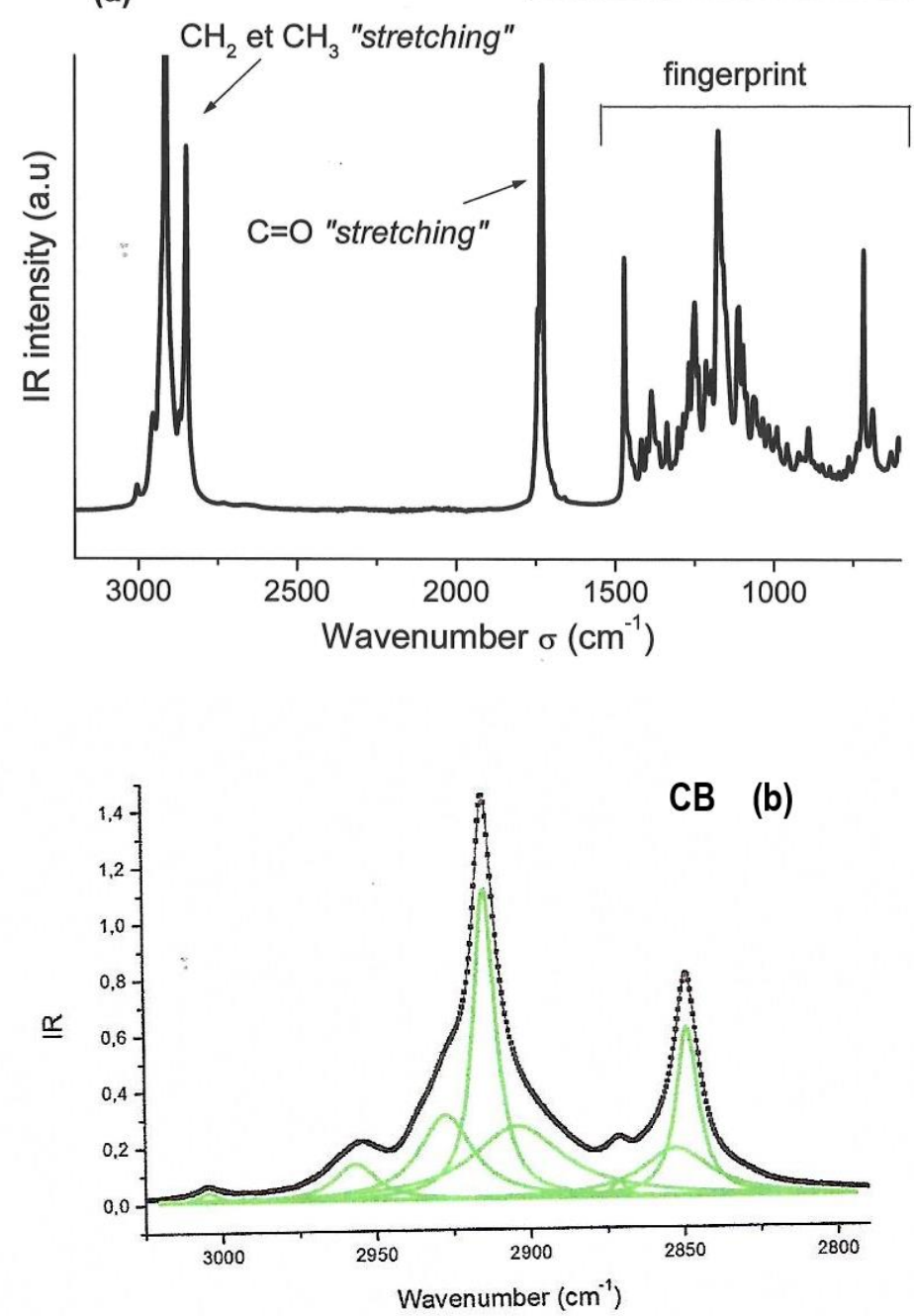

(c)

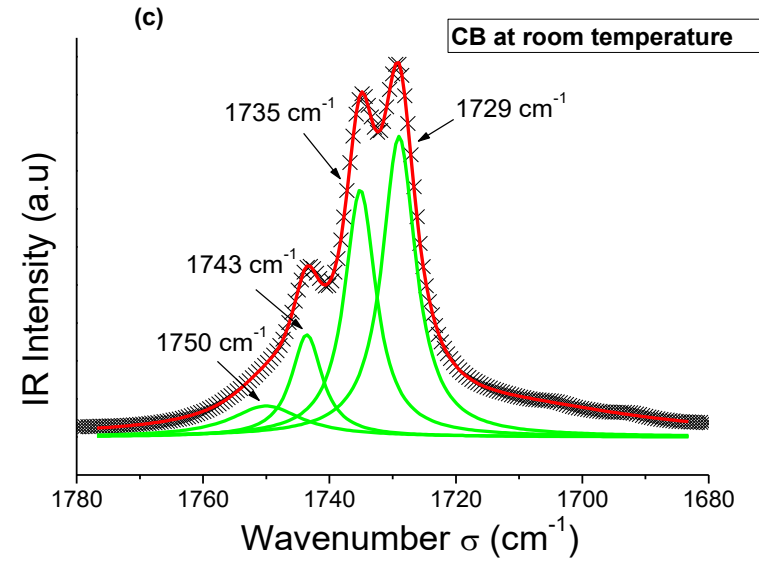

Fig. 4: IR spectra of cocoa butter $(\mathrm{CB})$ at room temperature $\left(\mathrm{T}=22{ }^{\circ} \mathrm{C}\right)$ in the spectral region 3050 to $600 \mathrm{~cm}^{-1}$ (a), 1800 to $1700 \mathrm{~cm}^{-1}$ (b) and 3050 to $2700 \mathrm{~cm}^{-1}$ (c). The crosses are the experimental points and the lines represent the components modelled by Lorentzian functions (green lines: components, red line: resultant of the components). 
In Fig. 4b), we present the MIR spectrum of CB in the spectral region 1800-1700 $\mathrm{cm}^{-1}$. In this figure, the crosses correspond to the experimental points and the lines are the components fitted by Lorentzian functions. The values in frequencies of the modes are obtained by the modelizations carried out by the software ORIGIN.8 of OriginLab Corporation ). The modeling method is proposed by Bresson et al. (Bresson et al, 2005). The error was estimated to be \pm 0.5 $\mathrm{cm}^{-1}$. The MIR spectra were all normalized to the peak at $1729 \mathrm{~cm}^{-1}$. In Fig. 4b), we can observe 4 distinct components: two intense peaks at $1729 \mathrm{~cm}^{-1}$ and $1735 \mathrm{~cm}^{-1}$, a moderately intense peak but well defined at $1743 \mathrm{~cm}^{-1}$, and a weaker peak at $1750 \mathrm{~cm}^{-1}$. These four peaks all correspond to vibrations of elongation of the $\mathrm{C}=0$ bonds of the carboxyl groups of the triglycerides.

The spectral region $3200-2700 \mathrm{~cm}^{-1}$ corresponds to the elongation vibration of the C-H single bonds of the triglycerides in the sample. The MIR spectrum and the modeling of the spectrum by Lorentzian functions are shown in Fig. 4c). We observe many components: a very weak peak at $3000 \mathrm{~cm}^{-1}$, a peak of medium intensity at $2956 \mathrm{~cm}^{-1}$, a very intense peak at $2914 \mathrm{~cm}^{-1}$ with a shoulder on both sides: one at $2927 \mathrm{~cm}^{-1}$ and one at $2903 \mathrm{~cm}^{-1}$, a fine and very weak but sharp peak at $2871 \mathrm{~cm}^{-1}$ and a fine and intense peak at $2849 \mathrm{~cm}^{-1}$ with a shoulder at $2852 \mathrm{~cm}^{-1}$. The peak assignment is given in Table S5, from the literature (Socrates, 2004).

\subsection{2) Cocoa Butter Equivalent (CBE)}

In Figs. S6, we present the two MIR spectra superimposed between CB and CBE for the three active spectral zones $3000-2800 \mathrm{~cm}^{-1}, 1800-1700 \mathrm{~cm}^{-1}$ and $1500-600 \mathrm{~cm}^{-1}$. It can be seen that the spectra are similar. Regarding the fingerprint, the two spectra seem identical. This confirms that the composition of the two butters are the same.

In the spectral region $1800-1700 \mathrm{~cm}^{-1}$, we observe the same four components as CB: two intense peaks at $1729 \mathrm{~cm}^{-1}$ and $1735 \mathrm{~cm}^{-1}$, a moderately intense but well defined peak at $1743 \mathrm{~cm}^{-1}$, as well as a lower intensity peak at $1751 \mathrm{~cm}^{-1}$.

In the spectral region $3100-2800 \mathrm{~cm}^{-1}$, we observe the same eight fitted components as for CB: a peak of very weak intensity at $3004 \mathrm{~cm}^{-1}$, a peak of average intensity at $2957 \mathrm{~cm}^{-1}$, a very weak peak, a very intense peak at $2914 \mathrm{~cm}^{-1}$ with a shoulder on both sides: one at 2927 $\mathrm{cm}^{-1}$ and another at $2903 \mathrm{~cm}^{-1}$, a fine and very weak peak but clear at $2871 \mathrm{~cm}^{-1}$ and a fine and intense peak at $2849 \mathrm{~cm}^{-1}$ with a shoulder at $2853 \mathrm{~cm}^{-1}$. The peaks are located at the same values in $\mathrm{cm}^{-1}$. 
To sum up, the fingerprints of the MIR spectra confirm that $\mathrm{CB}$ and $\mathrm{CBE}$ have the same triglycerides. The origin of the TG in the two butters is different, as well as the proportion of the three main triglycerides. It has also been observed that CB and CBE have a generally similar vibrational behavior in MIR spectroscopy at room temperature. To conclude, MIR spectroscopy does not seem to differentiate the two butters studied. In the following paragraph, we will analyze the Raman spectra at room temperature in order to determine whether there are vibrational markers of differentiation between $\mathrm{CB}$ and $\mathrm{CBE}$.

\subsection{FT Raman investigations}

\subsubsection{Cocoa butter $(\mathrm{CB})$}

The Raman spectrum of cocoa butter at room temperature $\left(T=22{ }^{\circ} C\right)$ in the spectral region $3200-500 \mathrm{~cm}^{-1}$ is shown in Fig. S7. We observe bands on the spectrum grouped by regions:

- the spectral region $3200-2700 \mathrm{~cm}^{-1}$ corresponding to the vibration of elongation of carbon-hydrogen single bonds, denoted $v(C-H)$ ("stretching mode");

- the spectral region $1800-1700 \mathrm{~cm}^{-1}$ corresponding to the vibration of elongation of carbon-oxygen double bonds, denoted $v(C=O)$ (ester carbonyl stretching region),

- the spectral region $1700-1600 \mathrm{~cm}^{-1}$ corresponding to the vibration of elongation of carbon-carbon double bonds, denoted $v(C=C$ ) (stretching region (olefinic band)),

- the spectral region 1500-1400 $\mathrm{cm}^{-1}$ corresponding to the scissoring of carbon-hydrogen single bonds, noted $\delta(C-H)$ (scissoring region),

- the spectral region $1400-1200 \mathrm{~cm}^{-1}$ corresponding to the twisting of carbon-hydrogen single bonds, denoted $\tau(C-H)$ (twisting region),

- the spectral region $1150-1000 \mathrm{~cm}^{-1}$ corresponding to the vibration of elongation of carbon-carbon single bonds, denoted $v(C-C)$ (stretching region).

It is observed in Fig. S8 that the vibrations of elongation $v(C-H)$ of $\mathrm{C}-\mathrm{H}$ bonds are active in MIR spectroscopy and also in Raman spectroscopy. In figure S7, we see that the vibrations $v(C$ $=C)$ are active in Raman spectroscopy while they were not in MIR. Moreover, it can be noted that the vibration zone of the $\mathrm{C}=\mathrm{O}$ carbonyl group is active in both spectroscopies. We can conclude that these two types of spectroscopies are quite complementary. In addition, the comparison between MIR and Raman spectra clearly demonstrated the interest of Raman spectroscopy. In fact, the carbon-carbon double bonds of the carboxyl groups of triglycerides vibrate in Raman but not in MIR. The assignment of the different modes observed in Raman spectroscopy for CB are identical to those presented by Bresson et al. (Bresson et al, 2011). 


\subsubsection{Cocoa Butter Equivalent (CBE)}

X-ray diffraction demonstrates a difference in polymorphic structure between $\mathrm{CB}$ and $\mathrm{CBE}$ at room temperature. It is therefore interesting to compare Raman spectra of $\mathrm{CB}$ and $\mathrm{CBE}$ in order to see whether the difference in polymorphic structure is noticed on Raman spectra.
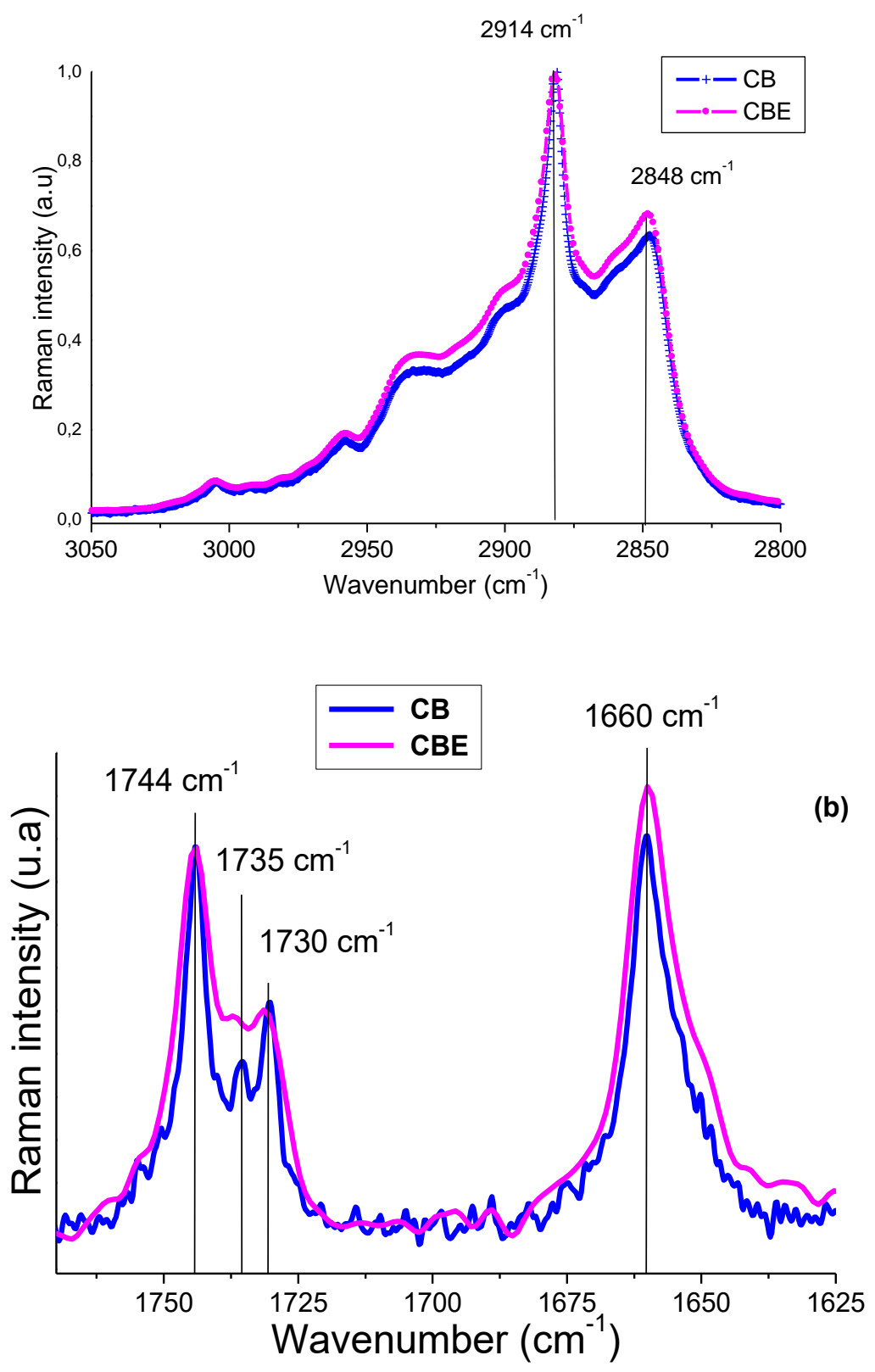

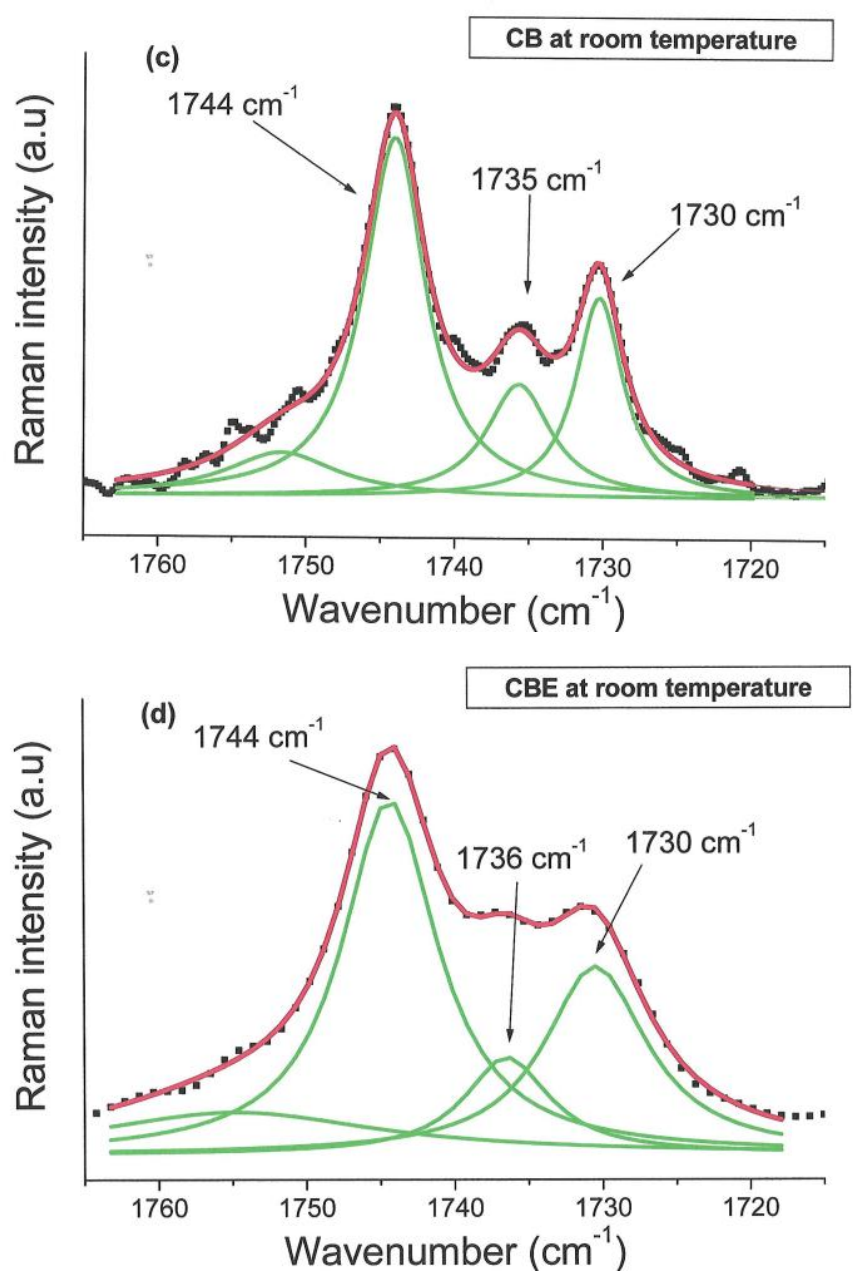

Fig. 5: Raman spectra of $\mathrm{CB}$ and $\mathrm{CBE}$ at room temperature $\left(\mathrm{T}=22{ }^{\circ} \mathrm{C}\right)$; at the incident wavelength $\lambda_{0}=1064 \mathrm{~nm}$ in the spectral region 3050 to $2800 \mathrm{~cm}^{-1}$ (a), 1800 to 1700 $\mathrm{cm}^{-1}$ (b), Raman spectra of cocoa butter (CB) (c) and CBE (d) modelled by Lorentzian functions in the $1800-1700 \mathrm{~cm}^{-1}$ spectral region.

In Figs. 5a) and 5b), we present the overlays of Raman spectra of $\mathrm{CB}$ and $\mathrm{CBE}$ in spectral regions $3050-2650 \mathrm{~cm}^{-1}$ and $1800-1625 \mathrm{~cm}^{-1}$ at room temperature. We first notice that the peaks do not seem to be shifted (in $\mathrm{cm}^{-1}$ ). The peaks with the greatest intensities are located at 2882 $\mathrm{cm}^{-1}$ and $2849 \mathrm{~cm}^{-1}$ in the vibration range $v(C-H)$; at $1744 \mathrm{~cm}^{-1}, 1735 \mathrm{~cm}^{-1}$ and $1730 \mathrm{~cm}^{-1}$ for vibrations of type $v(C=O)$; and $1660 \mathrm{~cm}^{-1}$ for the elongation vibrations $v(C=C)$. The spectra of Fig. 5a)) were normalized to the peak at $2882 \mathrm{~cm}^{-1}$ to allow easier comparison of the two spectra. The vibration zone $v(C=O)$ (Fig. 5b)) was normalized to the peak at $1744 \mathrm{~cm}^{-1}$.

The zones of vibration $v(C-H)$ and $v(C=C)$ do not seem to be very different between the two spectra. On the other hand, the two spectra in the vibration zone $v(C=O)$ seem quite different, 
particularly at the level of the intensity of the peak at $1735 \mathrm{~cm}^{-1}$. In order to be more precise in the analysis, we carry out the modeling by Lorentzian functions of Raman spectra of CB and CBE in the area 1800-1700 $\mathrm{cm}^{-1}$ (see Fig. 5c) and Fig. 5d)), we observe 3 components between 1750 and $1725 \mathrm{~cm}^{-1}: 1744 \mathrm{~cm}^{-1}, 1735$ and $1730 \mathrm{~cm}^{-1}$.

Bresson et al. have isolated the 6 polymorphic forms of CB and performed Raman spectrum of each form (Bresson et al, 2011). Modeling by Lorentzian functions of the spectra in the area $v(C=O)$ allowed them to identify a unique mode of vibration for the forms I and II at $1742 \mathrm{~cm}^{-1}$; two modes (two components) for forms III and IV at 1732 and $1744 \mathrm{~cm}^{-1}$; and three modes (three components) for V and VI forms (a triplet resolved at 1732, 1737 and $1745 \mathrm{~cm}^{-1}$ for V form and two components resolved at 1732 and $1746 \mathrm{~cm}^{-1}$ as well as a shoulder at $1740 \mathrm{~cm}^{-1}$ for form VI).

According to these authors, we can deduce that the mode at $1735 \mathrm{~cm}^{-1}$ for $\mathrm{CB}$ and at $1736 \mathrm{~cm}^{-1}$ for CBE comes from form V or VI. Let us recall that our studies in X-ray diffraction at room temperature has shown that the TG of the sample of CB were found only in form VI, but that some TG of CBE were crystallized in form IV (and others in form VI). It therefore seems interesting to compare the proportion of the three Lorentzian components of $\mathrm{CB}$ and $\mathrm{CBE}$ spectra of Figs. 5c) and 5d). For that reason, one can group together the values of the areas of each peak determined by the modelizations in table S9. In order to be able to compare these values, one carries out reports of areas of each mode for the two samples.

The area ratios of the three components are very different between $\mathrm{CB}$ and $\mathrm{CBE}$, which clearly shows that the modes of the vibrations $v(C=O)$ are markers of differentiation between the two cocoa butters. In addition, there is a very large difference between the area ratio $r_{1}=A_{1735} / A_{1730}$ of $\mathrm{CB}$ and that of CBE (see table S10). Indeed, the value of this ratio is almost twice as important for CB than CBE. This shows that the vibration mode at $1735 \mathrm{~cm}^{-1}$ of $\mathrm{CB}$ is more important than that of CBE compared to the mode at $1730 \mathrm{~cm}^{-1}$.

However, Bresson et al suggested that the mode at $1735 \mathrm{~cm}^{-1}$ was present for form VI of CB but not for form IV, while the mode at $1730 \mathrm{~cm}^{-1}$ is observed for both $\mathrm{CB}$ in form IV and form VI (Bresson et al, 2011). If the ratio $r_{l}$ halves between CB and CBE, this means that the TG in form IV has increased in CBE. It can be concluded that the modes of vibrations $v(C=O)$ in Raman spectrosocpy are markers of differentiation between $\mathrm{CB}$ and CBE. These markers are consistent with the interpretation of diffractograms of $\mathrm{CB}$ and $\mathrm{CBE}$ at room temperature carried out above: the crystallized TGs of $\mathrm{CB}$ are in form VI $\left(3 L \beta_{2}\right)$ just like part of the TGs of CBE; 
on the other hand, some TG of CBE are found in form IV $\left(2 L \beta_{2}^{\prime}\right)$.

\section{Conclusion}

The first important obtained result comes from the ESI/MALDI-HRMS experiments: our samples of $\mathrm{CB}$ and $\mathrm{CBE}$ are identical with respect to the types of triglycerides in them, but regarding the three main triglycerides the components POS, SOS and POP, the proportions are different. We observe in $\mathrm{CB}$ that POS dominates in quantity compared to the other two (practically $50 \%$ of the total), while for CBE, POP plays this role (practically $46 \%$ of the total). DSC and X-ray diffraction investigations made it possible to carry out a structural study of cocoa butter (CB) and cocoa butter equivalent (CBE), aged several years, at room temperature. It is possible to determine that at room temperature the crystallized TGs of CB were all in form VI $\left(3 L \beta_{2}\right)$, but those of CBE were either in form VI or in form IV $\left(2 L \beta_{2}^{\prime}\right)$ linked to major POP triglycerides. Raman spectroscopy has proven to be a useful tool in demonstrating this difference in structure between the two cocoa butters at room temperature, according to the study of the spectral region of the carbonyl group (1800-1700 $\left.\mathrm{cm}^{-1}\right)$.

MIR spectroscopy confirmed the identical nature of TGs by fingerprint analysis. The study of the two crystallization and molten samples by X-ray diffraction and by DSC made it possible to identify that the TGs of $\mathrm{CB}$ and $\mathrm{CBE}$ crystallized after cooling to $1^{\circ} \mathrm{C} \cdot \mathrm{min}^{-1}$ from the liquid state according to the forms $2 L \alpha$ and $2 L \beta^{\prime}$ for $\mathrm{CB}$ without being able to identify whether they were forms $2 L \beta_{1}^{\prime}$ or $2 L \beta_{2}^{\prime}$. While for CBE, 3 forms could be identified $2 L \alpha, 2 L \beta_{1}^{\prime}$ and $2 L \beta_{2}^{\prime}$. This study proves that all these techniques are complementary to carry out the structural investigation of $\mathrm{CB}$ and $\mathrm{CBE}$ samples.

\section{Acknowledgment}

We would like to thank Quentin Arnould, technician of Walloon Agricultural Research Centre (CRA-W), who participated to FT-Raman and ATR/FTIR measurements. 


\section{REFERENCES}

Arishima T., Sagi N., Mori H and sato K. (1991). Polymorphism of POS. I. Occurrence and Polymorphic Transformation. JAOCS 68 (10), 710-715

Bisvas N., Cheov Y.L., Tan C.P., and Siov L.F. (2017). Physical, rheological and sensorial properties, and bloom formation of dark chocolate made with cocoa butter substitute (cbs). LWT-Food Science and Technology, 82, 420-428

Bresson S., El Marssi M., and Khelifa B. (2005). Raman spectroscopy investigation of various saturated monoacid triglycerides. Chemistry and physics of lipids, 134(2) :119129

Bresson S., Rousseau D., Ghosh S., El Marssi M., and Faivre V (2011). Raman spectroscopy of the polymorphic forms and liquid state of cocoa butter. European Journal of Lipid Science and Technology, 113(8):992-1004.

Briones D. and Aguilera J.M. (2005). Image analysis of changes in surface color of chocolate. Food Research International, 38(1) :87-94

Da Silva T.L.T, Grimaldi R., Gonçalves L.A.G. (2017). Temperature, time and fat composition effect on fat bloom formation in dark chocolate. Food Structure 14, 68 - 75

Ghazani S. M. and Marangoni A. G. (2018). New Insights into the $\beta$ polymorphism of1Palmitoyl, 2-Oleoyl, 3-Srearoyl Glycerol. Cryst. Growth Des. 18, 4811-4814.

Ghazani S. M. and Marangoni A. G. (2019). The Triclinic Polymorphism of Cocoa Butter Is Dictated by Its Major Molecular Species, 1-Palmitoyl, 2-Oleoyl, 3-Srearoyl Glycerol (POS). Cryst. Growth Des. 19, 90-107

Gibon V., Durant F. and Deroanne. Cl. (1986). Polymorphism and intersolubility of Same Palmitic, Steraic and Oleic Triglycerides: PPP, PSP and POP. JAOCS, 6 (8), 1047-1055

Hartel R.W.(1999). Chocolate: fat bloom during storage. Manufacturing Confectioner,79:89-99

Reinke S., Roth S.V.,.Santoro G, Vieiras J., Heinrich S., and Plazer S. (2015) Tracking structural changes in lipid-based multi component food materials due to oil migration by microfocus small-angles x-ray. ACS applied materials and interfaces, 7(18):9929-9936 
Sato K., Arishima T., Wang Z.H., Ojima K., Sagi N. and Mori H. (1989). Polymorphismof POP and SOS. I. Occurrence and Polymorphic Transformation. JAOCS, 66 (5), 664-674

Socrates G. (2004). Infrared and Raman characteristic group frequencies tables and charts. John Wiley \& Sons

Sonvai S. and Rousseau D. (2008). Fat crystal growth and microstructural evolution in industrial milk chocolate. Crystal Growth and Design, 8(9) :3165-3174

Wille R.L. and Lutton E.S, 1966. Polymorphism of cocoa butter. Journal of the American Oil Chemists Society, 43(8):491-496 


\section{Supplementary material}

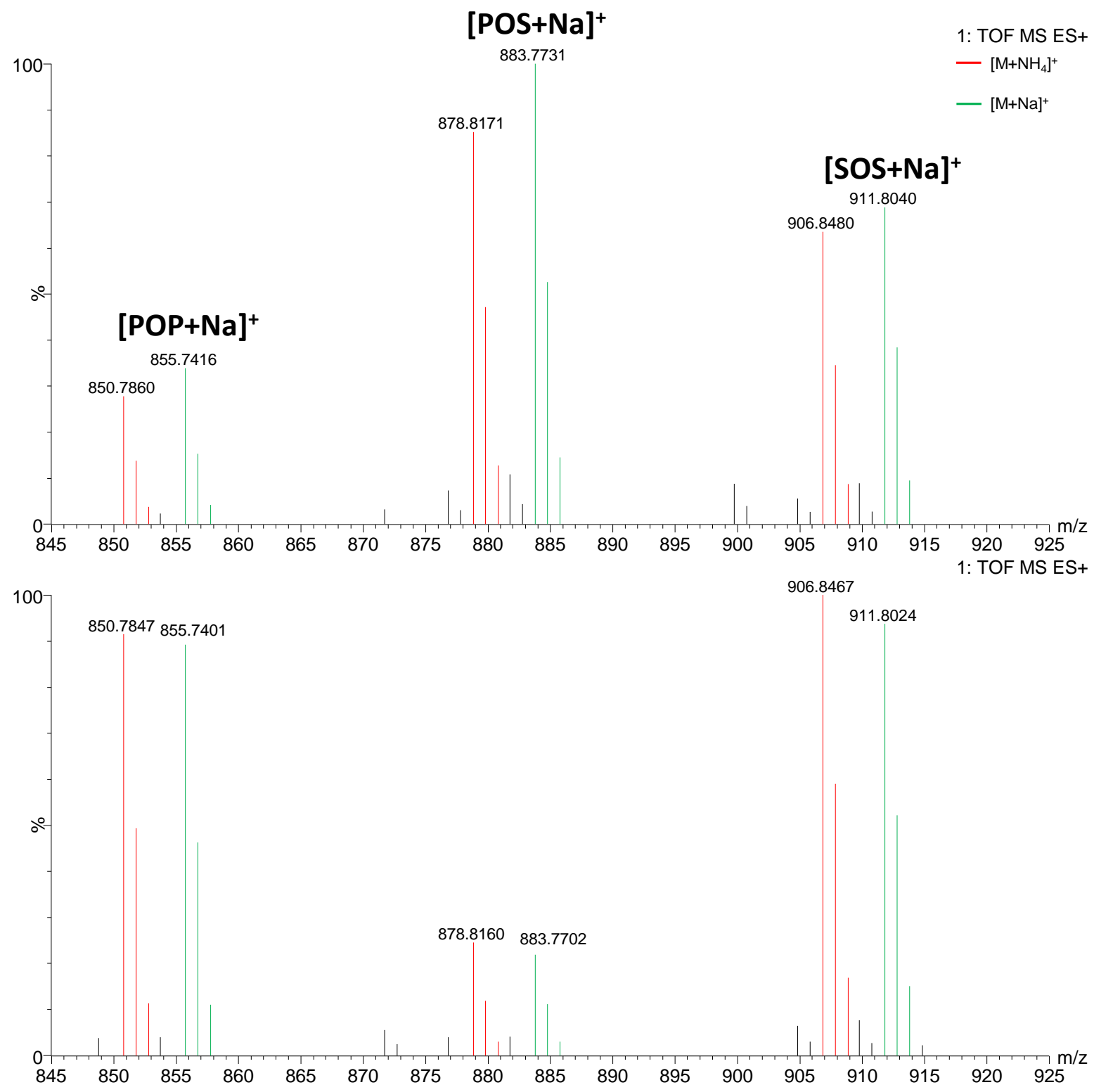

Fig. S1 : CB (top) and CBE (bottom) triglycerides mass region (845-925 u) obtained from ESI ionization. 
Fig S2
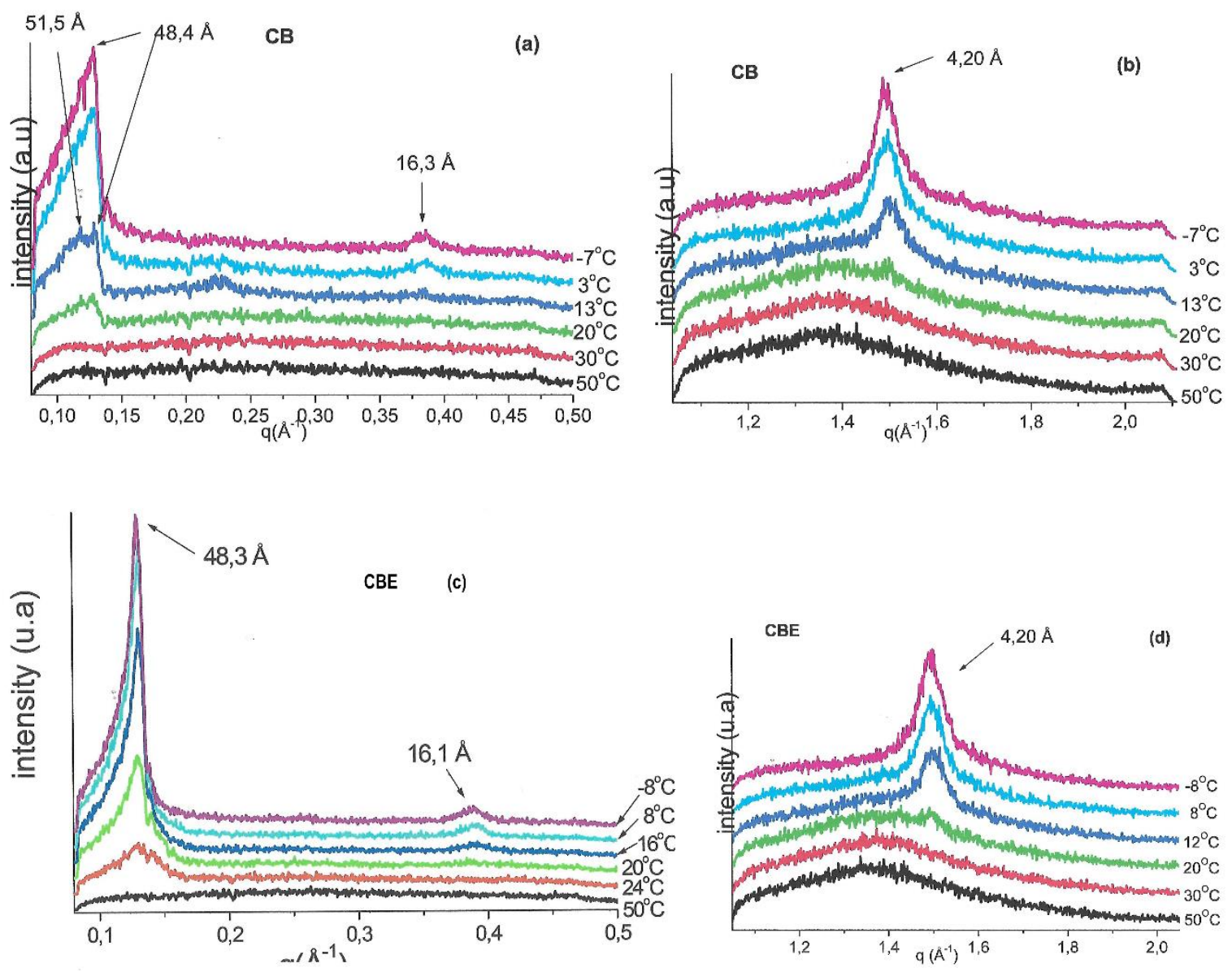

XRay diffractograms of CB : SAXS (a) and WAXS (b) configurations after cooling from $50{ }^{\circ} \mathrm{C}$ to $-7{ }^{\circ} \mathrm{C}$ at $1{ }^{\circ} \mathrm{C} / \mathrm{min}$ and of CBE: SAXS (c) and WAXS (d) configurations after cooling from $50{ }^{\circ} \mathrm{C}$ to $-8{ }^{\circ} \mathrm{C}$ at $1{ }^{\circ} \mathrm{C} / \mathrm{min}$ to study the crystallization of the TGs 
Table S3

\begin{tabular}{|c|c|c|}
\hline $\begin{array}{l}\text { Crystalline } \\
\text { organization }\end{array}$ & $\begin{array}{l}\text { CB at room temperature (22 } \\
\left.{ }^{o} \mathrm{C}\right)\end{array}$ & $\mathrm{CBE}$ at room temperature $\left(22^{\circ} \mathrm{C}\right)$ \\
\hline $\begin{array}{l}\text { long d-spacings, } \\
\text { type () } \\
\text { and intensity () }\end{array}$ & $\begin{array}{l}63.7 \AA\left(3 L \beta_{2}\right)(\mathrm{vs}) \\
31.9 \AA\left(3 L \beta_{2}\right)(\mathrm{vs})\end{array}$ & $\begin{array}{c}62.8 \AA\left(3 L \beta_{2}\right)(\mathrm{vs}) \\
42.7 \AA\left(2 L \beta_{2}^{\prime}\right)(\mathrm{s}) \\
31.6 \AA\left(3 L \beta_{2}\right)(\mathrm{vs})\end{array}$ \\
\hline $\begin{array}{l}\text { short d-spacings, } \\
\text { type () } \\
\text { and intensity () }\end{array}$ & $\begin{array}{l}5.36 \AA\left(3 L \beta_{2}\right)(\mathrm{w}) \\
4.60 \AA\left(3 L \beta_{2}\right)(\mathrm{vs}) \\
3.89 \AA\left(3 L \beta_{2}\right)(\mathrm{w}) \\
3.70 \AA\left(3 L \beta_{2}\right)(\mathrm{w})\end{array}$ & $\begin{array}{l}5.38 \AA\left(3 L \beta_{2}\right)(\mathrm{w}) \\
4.60 \AA\left(3 L \beta_{2}\right)(\mathrm{vs}) \\
3.89 \AA\left(3 L \beta_{2}\right)(\mathrm{w}) \\
3.73 \AA\left(3 L \beta_{2}\right)(\mathrm{w})\end{array}$ \\
\hline
\end{tabular}

Crystalline parameters of polymorphic forms of $C B$ and $C B E$ at room temperature $\left(22{ }^{\circ} C\right)$ after storage for six years. The values were determined by X-ray diffraction. Legend: $w$-weak; m-medium, s-strong; vs - very strong.

\section{Table S4}

\begin{tabular}{|c|c|c|c|c|}
\hline $\begin{array}{c}\text { Crystalline } \\
\text { organization }\end{array}$ & $\mathrm{CB}$ at $-7^{\circ} \mathrm{C}$ & $\mathrm{CBE}$ at $-8^{\circ} \mathrm{C}$ & $\mathrm{CB}$ at $13^{\circ} \mathrm{C}$ & $\mathrm{CBE}$ at $12^{\circ} \mathrm{C}$ \\
\hline $\begin{array}{c}\text { Long d-spacings, } \\
\text { type () } \\
\text { and intensity () }\end{array}$ & $\begin{array}{r}51,5 \AA(2 L \alpha)(\mathrm{vs}) \\
48,4 \AA\left(2 L \beta^{\prime}\right)(\mathrm{vs}) \\
16,3 \AA(2 L)(\mathrm{w})\end{array}$ & $\begin{array}{r}51,5 \AA(2 L \alpha)(\mathrm{s}) \\
48,4 \AA\left(2 L \beta^{\prime}\right)(\mathrm{vs}) \\
16,2 \AA(2 L)(\mathrm{w})\end{array}$ & $\begin{array}{c}52,5 \AA(2 L \alpha)(\mathrm{vs}) \\
48,4 \AA\left(2 L \beta^{\prime}\right)(\mathrm{vs}) \\
28,8 \AA(2 L)(\mathrm{w}) \\
16,6 \AA(2 L)(\mathrm{w})\end{array}$ & $\begin{array}{c}52,3 \AA(2 L \alpha)(\mathrm{s}) \\
48,3 \AA\left(2 L \beta^{\prime}\right)(\mathrm{vs}) \\
28,6 \AA(2 L)(\mathrm{w}) \\
16,3 \AA(2 L)(\mathrm{w})\end{array}$ \\
\hline $\begin{array}{c}\text { Short d-spacings, } \\
\text { type () } \\
\text { and intensity () }\end{array}$ & $\begin{array}{c}4,20 \AA(2 L \alpha \\
\left.2 L \beta^{\prime}\right)(\mathrm{vs})\end{array}$ & $\begin{array}{c}4,20 \AA(2 L \alpha \\
\left.2 L \beta^{\prime}\right)(\mathrm{vs})\end{array}$ & $\begin{array}{c}4,18 \AA(2 L \alpha \\
\left.2 L \beta^{\prime}\right)(\mathrm{vs})\end{array}$ & $\begin{array}{c}4,18 \AA(2 L \alpha \\
\left.2 L \beta^{\prime}\right)(\mathrm{vs})\end{array}$ \\
\hline
\end{tabular}

Crystalline parameters of polymorphic forms of $\mathrm{CB}$ and $\mathrm{CBE}$ during their crystallization at $1{ }^{\circ} \mathrm{C} . \mathrm{min}^{-1}$. The values were determined by $X$-ray diffraction. Legend: $w$-weak; $m$-medium, $s$-strong; vs-very strong

\section{Table S5}

\begin{tabular}{|c|c|c|c|}
\hline Component & CB & CBE \\
\hline \multirow{2}{*}{$1744 \mathrm{~cm}^{-1}$} & Area $A_{1744}(\mathrm{a} . \mathrm{u})$ & 6.5 & 10.4 \\
& Half width $\left(\mathrm{cm}^{-1}\right)$ & 5.0 & 7.9 \\
\hline \multirow{2}{*}{$1735 \mathrm{~cm}^{-1}$} & Area $A_{1735}(\mathrm{a} . \mathrm{u})$ & 2.2 & 2.5 \\
& Half width $\left(\mathrm{cm}^{-1}\right)$ & 5.3 & 6.9 \\
\hline \multirow{2}{*}{$1730 \mathrm{~cm}^{-1}$} & Area $A_{1730}(\mathrm{a} . \mathrm{u})$ & 2.8 & 5.9 \\
& Half width $\left(\mathrm{cm}^{-1}\right)$ & 3.9 & 8.4 \\
\hline
\end{tabular}

Areas of the components of the Lorentzian modelizations of Raman spectra of cocoa butter $(C B)$ and $C B E$ at room temperature $\left(T=22^{\circ} C\right)$. 


\section{Fig S6}
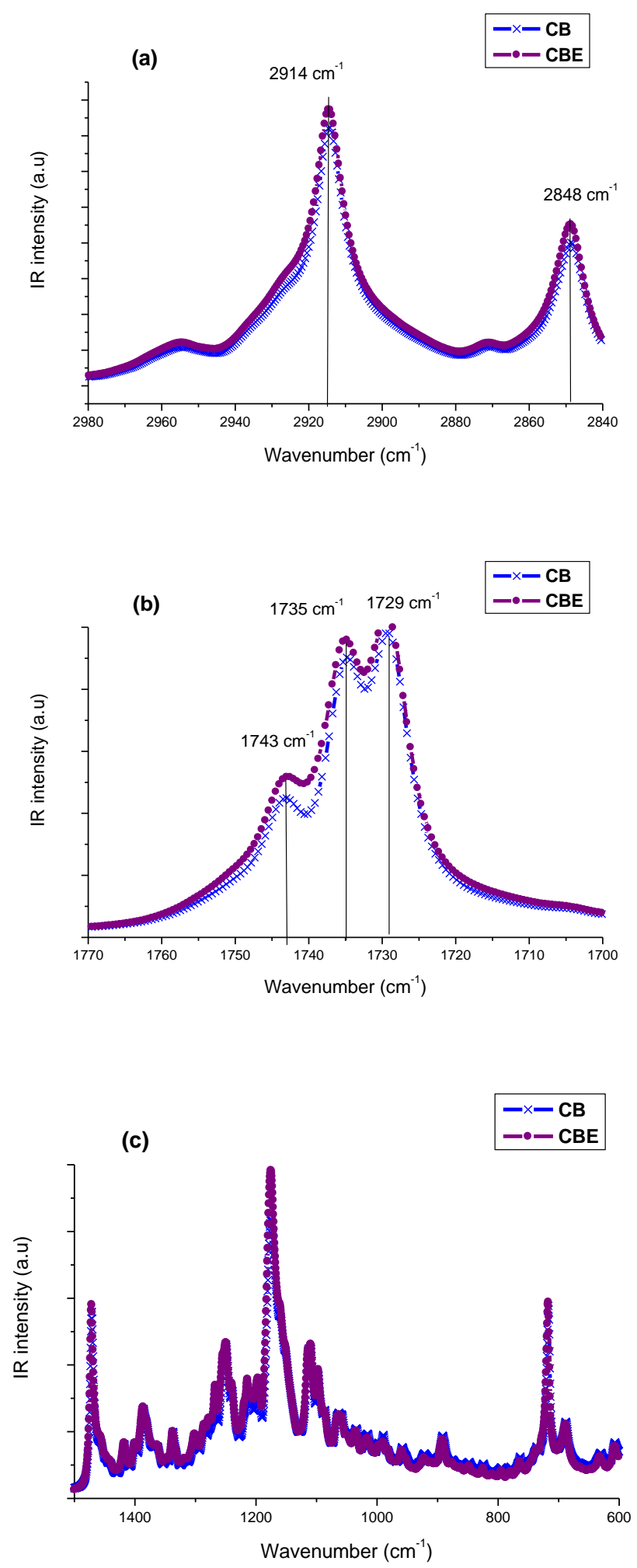

Comparison of MIR spectra of $\mathrm{CB}$ and $\mathrm{CBE}$ at room temperature $\left(\mathrm{T}=22^{\circ} \mathrm{C}\right)$ in the spectral region 3050 to $2800 \mathrm{~cm}^{-1}$ (a), 1800 to $1700 \mathrm{~cm}^{-1}$ (b) and 1500 to $600 \mathrm{~cm}^{-1}$ (c) 
Fig S7

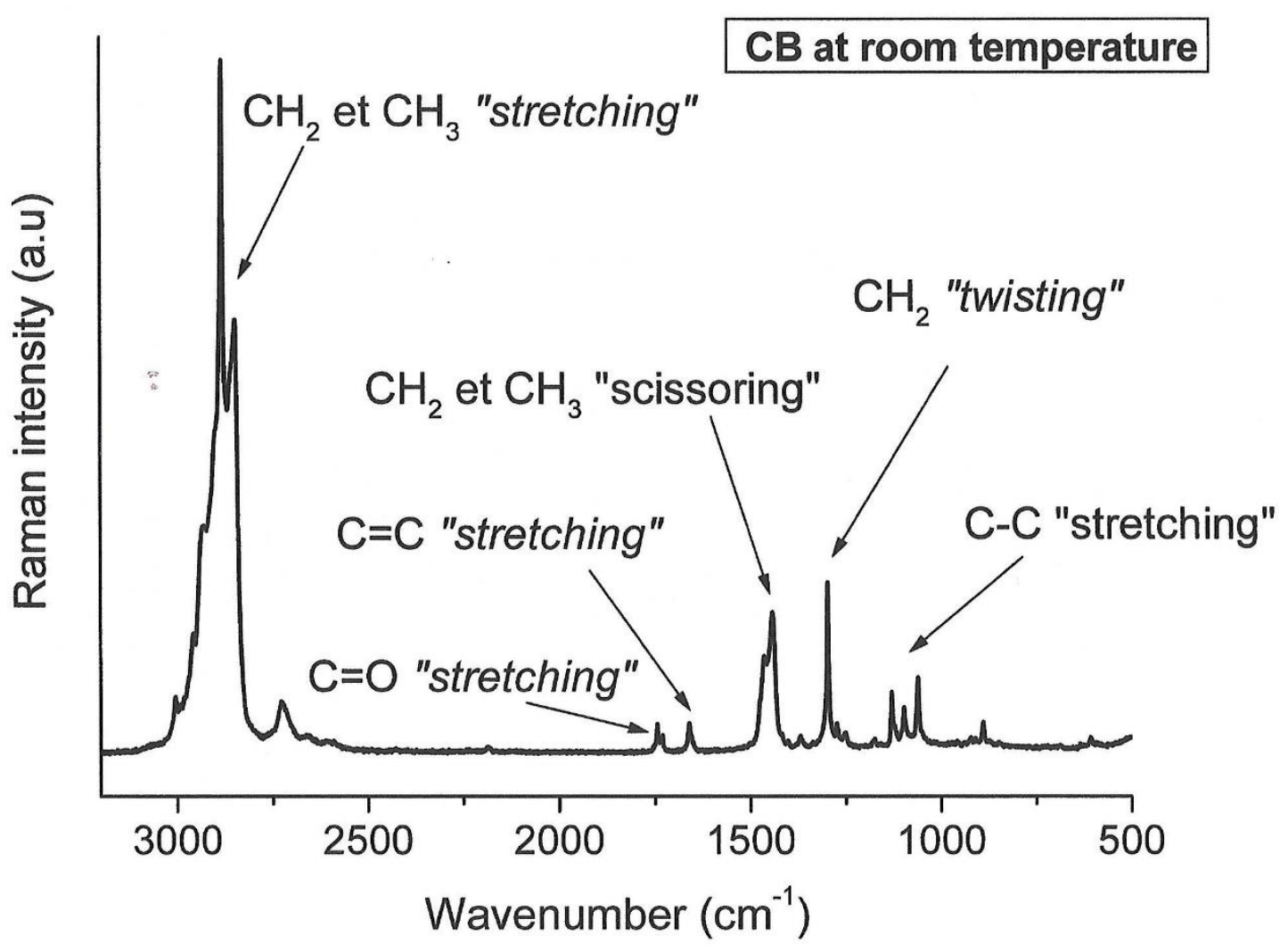

Raman spectra of cocoa butter $(\mathrm{CB})$ at room temperature $\left(\mathrm{T}=22{ }^{\circ} \mathrm{C}\right)$ from 3050 to 600 $\mathrm{cm}^{-1}$ 


\section{Fig S8}
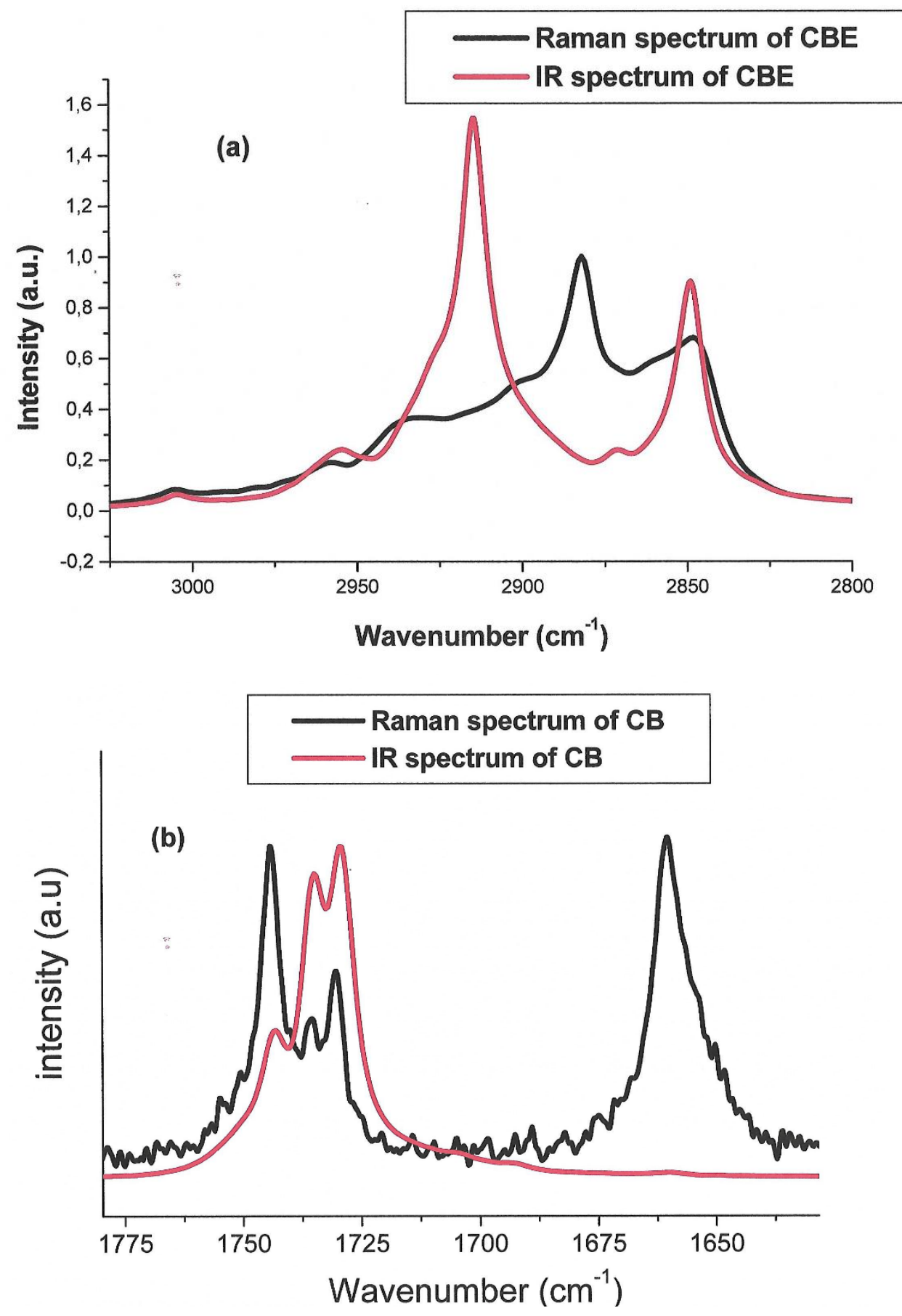

Comparison of Raman and MIR spectra of cocoa butter $(\mathrm{CB})$ at room temperature $(\mathrm{T}=22$

${ }^{\circ} \mathrm{C}$ ) in the $3050-2700 \mathrm{~cm}^{-1}$ spectral region (a) and $1800-1700 \mathrm{~cm}^{-1}$ spectral region (b). 


\section{Table S9}

\begin{tabular}{|c|c|l|c|}
\hline Component & CB & CBE \\
\hline \multirow{2}{*}{$1744 \mathrm{~cm}^{-1}$} & Area $A_{1744}(\mathrm{a} . \mathrm{u})$ & 6.5 & 10.4 \\
& Half width $\left(\mathrm{cm}^{-1}\right)$ & 5.0 & 7.9 \\
\hline \multirow{2}{*}{$1735 \mathrm{~cm}^{-1}$} & Area $A_{1735}(\mathrm{a} . \mathrm{u})$ & 2.2 & 2.5 \\
& Half width $\left(\mathrm{cm}^{-1}\right)$ & 5.3 & 6.9 \\
\hline \multirow{2}{*}{$1730 \mathrm{~cm}^{-1}$} & Area $A_{1730}(\mathrm{a} . \mathrm{u})$ & 2.8 & 5.9 \\
& Half width $\left(\mathrm{cm}^{-1}\right)$ & 3.9 & 8.4 \\
\hline
\end{tabular}

Areas of the components of the Lorentzian modelizations of Raman spectra of cocoa butter $(C B)$ and $C B E$ at room temperature $\left(T=22^{\circ} C\right)$.

Table S10

\begin{tabular}{|c|c|c|c|}
\hline Area Ratio & $\mathbf{C B}$ & $\mathrm{CBE}$ & $\left|\boldsymbol{r}_{\boldsymbol{C B}}-\boldsymbol{r}_{\boldsymbol{C B E}}\right| \boldsymbol{r}_{\boldsymbol{C B}}$ \\
\hline $\boldsymbol{r}_{\boldsymbol{1}}=\boldsymbol{A}_{1735} / \boldsymbol{A}_{1730}$ & 0.79 & 0.42 & $88 \%$ \\
\hline $\boldsymbol{r}_{2}=\boldsymbol{A}_{1735} / \boldsymbol{A}_{1744}$ & 0.34 & 0.24 & $30 \%$ \\
\hline $\boldsymbol{r}_{3}=\boldsymbol{A}_{1730} / \boldsymbol{A}_{1744}$ & 0.43 & 0.56 & $30 \%$ \\
\hline
\end{tabular}

Area ratio of the components of the Lorentzian modeling of Raman spectra of cocoa butter $(C B)$ and $C B E$ at room temperature $\left(T=22{ }^{\circ} C\right)$. 